\title{
Hacia el espacio público de calidad: \\ una mirada desde de Barranquilla
}

\section{To the public space of quality: a look from Barranquilla}

DOI: $10.17981 /$ mod.arq.cuc.18.2.2018.04

Fecha de Envío: 13/09/2018 Fecha de Aceptación: 11/09/2018

Carlos Avendaño, Maria Cuello Echeverry, Maria Diaz Pastrana, Jean Simmonds, Carolina Betancourth Plaza, Silvia Gasparini, Vialy Caballero Oviedo, Alvaro Morales Aragon, Juan Pacheco, Gleidys Vega Pinzon, Jose Imitola, Miguel Ortega Bernal, Andrea Ramirez Gonzalez, Angela Sofia Martinez y Katerine Arrauth Ochoa ${ }^{1}$

Universidad de la Costa, CUC (Colombia) carlosjo-el02@hotmail.com

Para citar este artículo:

Avendaño, C., Cuello, M., Diaz, M., Simmonds, J., Betancourth, C., Gasparini, S., Caballero, V., Morales, A., Pacheco, J., Vega, G., Imitola, J., Ortega, M., Ramirez, A., Martinez, A. y Arrauth, K. (2018). Hacia el espacio público de calidad: una mirada desde de Barranquilla. MODULO ARQUITECTURA-CUC, vol. 21, no. 1, pp. 97-130. DOI: 10.17981/mod.arq.cuc.18.2.2018.04

\section{Resumen}

Barranquilla en la búsqueda de su Re-conceptualización como ciudad integral, y en apuesta al mejoramiento de su infraestructura urbana, ha propuesto impulsar el potencial que representan los escenarios públicos en la cotidianidad de la ciudadanía; elementos dinamizadores como los parques y plazas, son tomados como piezas fundamentales para el estudio, análisis y crítica de su funcionalidad como ente estructurante del urbanismo en el presente artículo. Logrando de esta forma un comparativo entre la cantidad, calidad y eficiencia de los espacios públicos que posee la ciudad, teniendo en cuenta características de su estado, apreciación e importancia que representa para la población y el impacto de este elemento en el ámbito urbano. Obteniendo a raíz de esto, aspectos subjetivos y objetivos que permiten una valoración completa, con un abordaje sistémico del concepto de espacio público. Las variantes que se encuentran al analizar el espacio público en la ciudad dependen de su ubicación o contexto, área, componentes y población o área de influencia que es beneficiada con este; poniendo en disyuntiva los objetivos al comparar las muestras, con los criterios en que nos basamos para lograr una concepción de espacio público eficiente, pero al mismo tiempo rejido por las necesidades y requerimientos de sus habitantes, al ser concebido como espacio o área exterior de interés público; de todos y para todos, donde puedes ser libre de hacer lo que desees pero respetando el derecho de los demás ciudadanos.

Palabras clave: Espacio público, calidad, eficiencia, integración social, ente dinamizador.

\section{Abstract}

Barranquilla in the search of its Re-conceptualization as integral city and in bet to the improvement of its urban infrastructure, has proposed to promote the potential that represent the public scenarios in the daily life of the citizens, dynamic elements such as parks and squares, are taken as fundamental pieces for the study, analysis and critique of its functionality as structuring entity of urbanism in this article. Achieving in this way a comparison between the quantity, quality and efficiency of the public spaces that the city possesses, taking into account characteristics of its state, appreciation and importance that it represents for the population and the impact of this element in the urban environment. Obtaining as a result of this, subjective and objective aspects that allow a complete evaluation, a systemic approach of the concept of public space. The variants found when analyzing the public space in the city depend on its location or context, area, components and population or area of influence that is benefited with it, this puts in a dilemma of how to really be objective when comparing the samples, on what criteria can be based to achieve a conception of an efficient public space, but at the same time governed by the needs and requirements of those who inhabit it, which is conceived as all that space or exterior area that is public interest; of all and for all, where you can be free to do what you want but respecting the rights of other citizens.

Keywords: Public space, quality, efficiency, social integration, dynamic agent.

${ }^{1}$ Estudiantes de Arquitectura. Grupo ACUPUNTURA URBANA - Semillero de Investigación ARKCO - Universidad de la Costa, CUC.

- The author; licensee Universidad de la Costa - CUC.

Módulo Arquitectura CUC vol. 21 no. 1, pp. 97-130. Julio - Diciembre, 2018

Barranquilla. ISSN Impreso 0124-6542, ISSN Online 2389-7732 


\section{INTRODUCCION}

La "puerta de oro de Colombia", "curramba la bella", "la arenosa" o simplemente "Barranquilla, ciudad industrial y portuaria" es donde se dio lugar o ingreso a múltiples adelantos en el sector de la aviación, comunicación y cultura, entre muchos otros. A pesar de todo esto, la organización territorial y urbanismo de esta urbe no es digno de todo su potencial, debido a la configuración de la ciudad, al ser concebida desde sus inicios como asentamiento indígena debido a la posición estratégica que posee, al estar entre el rio y el mar. Hecho que marcó la pauta para el crecimiento de la ciudad, pero al mismo tiempo es un aspecto que desestima su valor; algo que en la actualidad se pretende rescatar. Hablar de espacio público eficiente, de calidad y entes dinamizador es complejo; pero hablar de él contextualizándolo para la ciudad de barranquilla es aún más, por lo anteriormente mencionado.

Barranquilla a pesar de ser cuna o puerta de entrada de muchos de los adelantos que arribaron al país, ha carecido desde siempre de una estructura o planeamiento territorial que configure a la ciudad de manera integral; en donde el uso del suelo y cada asentamiento o actividad urbana este organizado de manera eficiente. Ocasionado, por el hecho de haber sido generado de manera ocasional, debido a su crecimiento esporádico y a raíz de las necesidades y conveniencias de quienes construían este territorio.
En la actualidad Barranquilla desea fervorosamente convertirse y ser reconocida por ser una ciudad integral; y en esa medida una de las estrategias que han implementado los entes gubernamentales es invertir en el mejoramiento de las zonas verdes, espacios públicos y de recreación con los que cuenta la ciudad. ¿Pero será que la idea que se tiene de espacio público es la correcta? ¿Qué clase de espacio público se está construyendo? ¿El espacio público que se desarrolla en la ciudad obedece a las necesidades de su área de influencia o son simples "copy and paste"?

El proceso que lleva la ciudad para recuperar el espacio público para los ciudadanos es evidente, pero ¿con base a qué criterios están desarrollando la construcción de estas áreas?, ¿realmente podemos decir que se están construyendo espacios de calidad, eficientes y que a su vez sean entes dinamizadores para las comunidades?; esta es la razón por la cual este estudio es de valiosa importancia para conocer las condiciones, características y definiciones que se tiene por espacio público. Al hablar de espacio público nos estamos refiriendo a zonas, áreas, lugares o espacios para la libre expresión y la apropiación de los ciudadanos, como entes dinamizadores en la cotidianidad de las comunidades, que reúnen su identidad, crean vida colectiva y se convierten en espacios que permiten la integración con la naturaleza, el patrimonio, la cultura y la sociedad. 
Son más que simples parques, zonas verdes y de recreación; son espacios de todos y para todos, cuyo propósito es permitirle a la comunidad ser libre y desarrollarse bajo esa misma filosofía, pero al mismo tiempo respetando a todos los demás que lo conforman. La creación de espacio público no radica simplemente en la idea de construirlos, mantenerlos o intervenirlos, sino en un hecho social que altera positivamente las actividades colectivas de quienes pueden acceder a él; en pocas palabras son un ente relevante para la urbanidad de la ciudad, tal como la historia de la ciudad es la de su espacio público (Borja y Muxi, 2000)

Pero el espacio público además posee otras características que generan relevancia en los usuarios y en la comunidad, criterios de valoración y de entendimiento sobre el mismo, que permiten que sea visto, discernido y observado desde muchas perspectivas. Logrando al final de este análisis, materializar y considerar al espacio público como aquel lugar que es de todos, sea una zona verde, un área de recreación o un área sin ello, cubierto o descubierto, o cualquier característica, o atributo que esta posea, pues el principal propósito de este ya está siendo cumplido, al permitir la integración y desarrollo libre de las comunidades; lo demás son cualidades que refuerzan y aumentan la calidad y la eficiencia de estos espacios. Espacio público como
Io plantea Padilla (2015), es "todo lo que está por fuera de las edificaciones" y todo espacio que es compartido por la comunidad, en la medida en que entendemos que "también es considerado como todas las áreas exteriores de lo edificado, <<el vacío entre volúmenes arquitectónicos $>>$, que no tiene ni debe tener restricción de accesos" (Padilla, 2015, p. 142). Hallamos espacio público desde; transitar por una calle o vía pública, al caminar por un andén o bulevar, al estacionarse en una celda de parqueo publica, al correr en un parque o contemplar un atardecer en una plaza. Son espacios que existen en los crecimientos urbanos por su imperiosa necesidad.

Según Osorio y Rojas (2013) el espacio público es un principio social, un elemento determinante en los planes de ordenamiento territorial y prioritario en los panes de desarrollo, lo que refiere a que "si o si" deben estar localizados en la escenografía completa de la ciudad. pero la existencia de estos no asegura la calidad y funcionalidad de los mismos, puesto que depende de la manera en la que está configurado, conformado o estructurado; el tipo de uso, ya sea como zona recreativa para niños o espacio cultural. Si bien, ambos son espacio público, cada uno de ellos está desarrollado para y con condiciones específicas, que son determinadas por el estudio de la comunidad o área de influencia que este tipo de espacio impactará. 
“El espacio público, cuando es usado para comunicarse, transmite símbolos que, a la vez, son compartidos y contribuyen a diferenciar los usos que se hacen en el lugar para crear arraigo con el mismo; en este sentido es que se contribuye a la apropiación del espacio público" (Paramo y Burbano, 2014).

De esta manera se podría decir que el espacio público está hecho para múltiples funciones y una de ellas está basada en la comunicación. Pero un espacio público eficiente es conocido como el indicador que regula o que dictamina el espacio público por cada habitante, que a su vez define a este como: "el espacio público de carácter permanente, conformado por zonas verdes, parques, plazas y plazoletas" (República de Colombia, 2012). En Colombia, el Articulo 14 del Decreto 1504 de 1998 considera adecuadamente como índice mínimo de espacio público efectivo por habitante quince metros cuadrados $\left(15 \mathrm{~m}^{2}\right)$; pero, dentro de Colombia, la mayoría de ciudades, por no decir todas, se encuentran en un déficit de espacio público efectivo. No se llega ni siquiera al $1 \%$ de la cifra considerada por el decreto; como sucede en la ciudad de Barranquilla, cuyo problema está en la cantidad y la calidad de espacio público que se posee y el que se construye.

¿Cómo analizar y estudiar el espacio público que tiene la ciudad de Barranquilla, viendo a esté como los lugares que construyen ciudad y son entes dinamizadores en las urbes, como lo son las plazas y los parques? Para lograr esto se desarrolló una serie de procedimientos:

\section{Análisis situacional}

- Selección de los espacios de estudio: Se pretendieron seleccionar espacios que estuviesen desarrollados en diferentes puntos de la ciudad, para incluir explícitamente en el análisis la variabilidad de comunidades y estratos, y ver cómo estos influyen en la vida del espacio público.

\section{Análisis de transformación}

- Observación e interpretación del antes y el después: Gracias a las obras de la alcaldía de Barranquilla y a su plan de manejo de espacio público, se pudo apreciar la forma en que los parques y plazas fueron intervenidos, viendo la implementación de nuevas áreas y zonas de recreación, y nuevos y mejorados mobiliarios urbanos, permitiendo generar conclusiones a partir de comparaciones del antes y el ahora.

\section{Análisis de la calidad}

- Metodología PPS (Projects for public spaces): Esta metodología permite hacer un gran análisis del territorio desde 4 grandes dimensiones o enfoques; los usos y actividades, el confort e imagen, accesibilidad y enlace, y la sociabilidad. En este caso de análisis de espacio público las 4 dimensiones cumplieron un papel fundamental para determinar la calidad de cada espacio. 


\section{Construcción de} fichas de análisis

- Ficha \#1: Muestra la localización de cada uno de los espacios en estudio, su convergencia, la transformación que ha sufrido mediante la intervención de la alcaldía, una zonificación esquemática de las áreas y posibles actividades de los parques; la cual hace posible comparar la presencia de la alcaldía en cada una de las intervenciones de estos parques, y como las necesidades vistas en las comunidades fueron diferentes y especiales a los equipos y mobiliarios que se instalaron.

Ficha \# 1. Localización. Fuente: elaborado por los autores a partir de google maps.

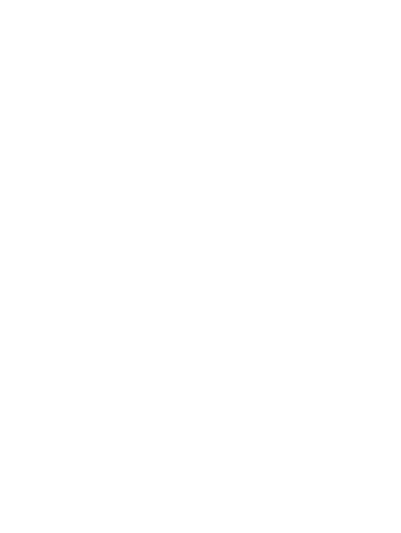

Ficha \# 2. Análisis de la calidad del espacio público Fuente: elaborado por los autores a partir de google maps.

- Ficha \#2: Muestra el análisis de la calidad de cada espacio público, gracias al uso de la metodología de PPS (Projects for public spaces), en el que se muestra una valoración de los parques con respecto a 4 dimensiones muy completas que analizan al territorio: 1) los usos y actividades, 2) el confort e imagen, 3) accesibilidad y 4) enlace, y la sociabilidad. Al final se presenta una apreciación sobre dicho análisis para concluir con el estado actual en que se encuentran estos espacios públicos, y a su vez plantear posibles soluciones enfocadas hacia las deficiencias que estos puedan tener, si es que las presentan.
Así pues, el estudio e investigación global que se obtuvo del espacio público en la ciudad de barraquilla, con el análisis de los 12 parques expuestos posteriormente, muestran la calidad y eficiencia de estos lugares, permitiendo encontrar y establecer comparativos que contribuyen en la conceptualización del estado y necesidades para construir ciudad, ya que esto se logra al partir de hacer verdaderos espacios públicos.

\section{2 espacios públicos}

- Parque Almendra

- Parque Bellavista

- Parque Cisneros
- Parque Cristo Rey

- Parque de los Sueños

- Parque de las Américas

- Parque la Cumbre

- Parque la Placita del Valle

- Parque los Andes

- Parque San Marino

- Parque Springfield

- Parque Virgen del Carmen

Reconocer como la calidad del espacio público de una ciudad está determinada por la capacidad de estos lugares de transformar e integrar la vida colectiva es completamente valido, 
sin embargo el minúsculo sentido de pertenencia y cultura ciudadana se ve reflejado en el responsabilidad de subsistencia Estado (Rocha, 2013). Pero, si la misma comunidad se involucra en los procesos de concepción del espacio público, bien sea poniéndose como autores y actores de su buena calidad, esta se ve mayormente prolongada, por el hecho de activar el sentido de pertenencia que anteriormente faltaba. Esta es una de las razones por las cuales la estrategia de la participación cludadana, como un es una garantia de la callad de miento que se tiene del territorio $y$ en especial de los espacios públicos es ser cos espacios con la realidad que las vivencias y todos los detalles que la gente que habita el lugar pueden proporcionar. De iqual manera se sigue fomentando y propiciando la creación de organizaciones comunitarias que, al interior de su visión, tengan como misión la construcción-apropiación colectiva del territorio (Yori, 2017)

Fig. 1. Infografía parque

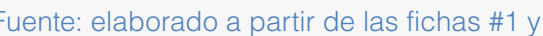

Parque San Marino

\section{LOCALIZACIÓN}

Esquina carrera $77^{a}$ con calle 87

ANTES (2000-2014)
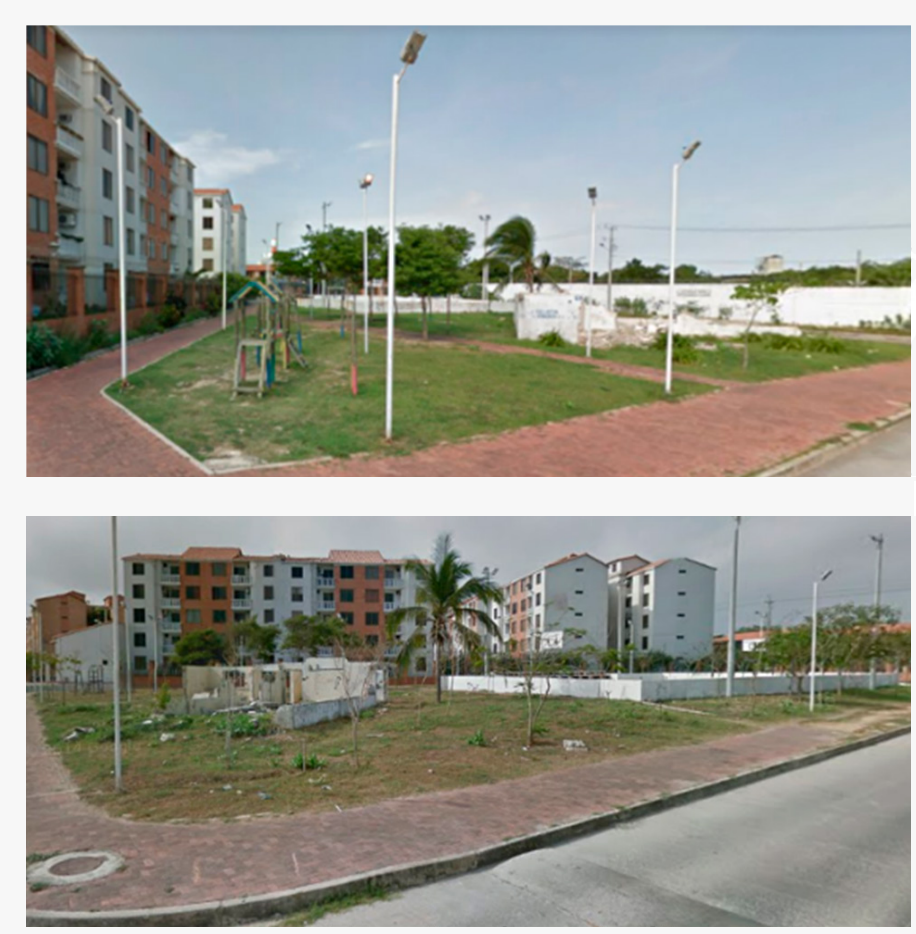

ZONIFICACIÓN

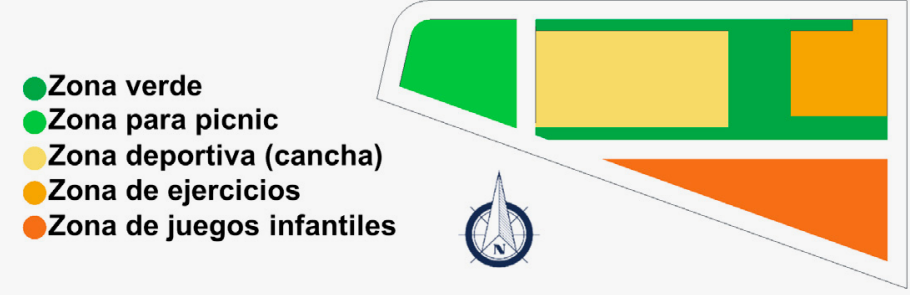

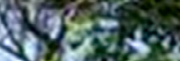




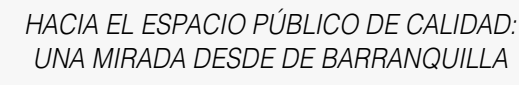

En esta medida también desarrollar un análisis reflexivo, no solo del territorio en una dimensión física o ecológica sino tambié desde el concepto de Participación Ciudadana-PC, obteniendo sus opiniones acerca de que necesitan, como viven e interactúan el espacio público. A la vez mediante estas tecnicas estamo en la busqueda de un lugar rea que exponga la esencia del territorio, el diseño urbano, en este contexto, evoluciono hacia un tipo producción de lugares significativos (Correa, 2013)

Además a través de estas y criticar, para tener una postura global del estado del espacio público y del equipamiento de recreación de los parques; de los cuales se infiere que poseen un estado eficiente y aceptable pero, la cantidad que se encuentra de ellos es insuficiente, del indice de espacio público del cual debe gozar o el cual se le debe proporcionar a cada ciudadano, por ende se entra en un debate entre la calidad y la cantidad de espacio

Fig. 2. Infografía Euente: elaborado a partir de las fichas
Parque Almendra

LOCALIZACIÓN

Carrera 32 con calle 38

ANTES (2015)
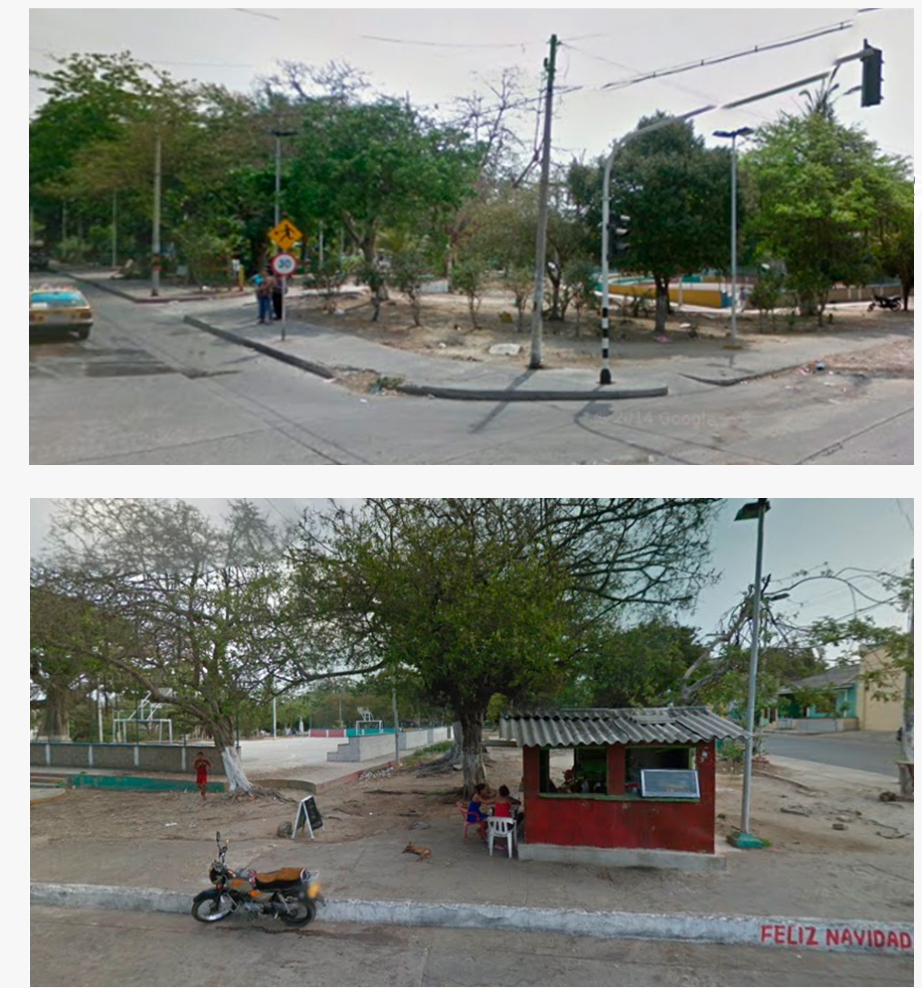

ZONIFICACIÓN

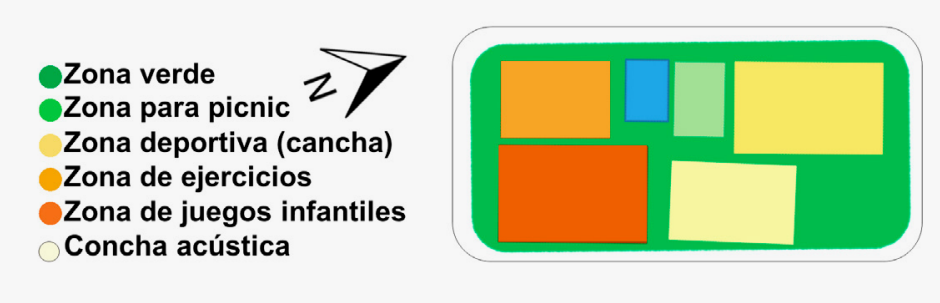

$\Rightarrow$

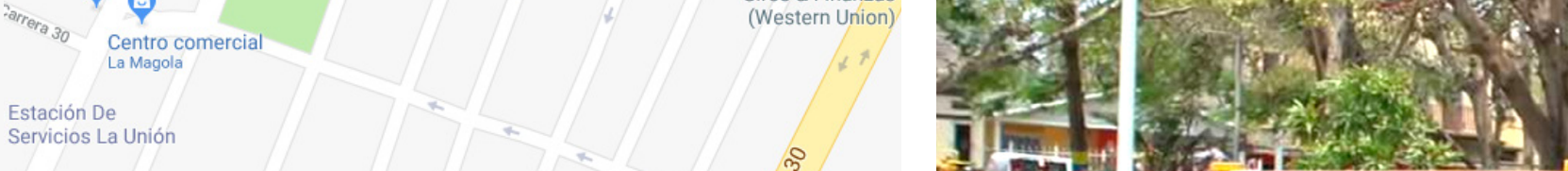

$a_{a \log a_{20}}$

\section{(1)}

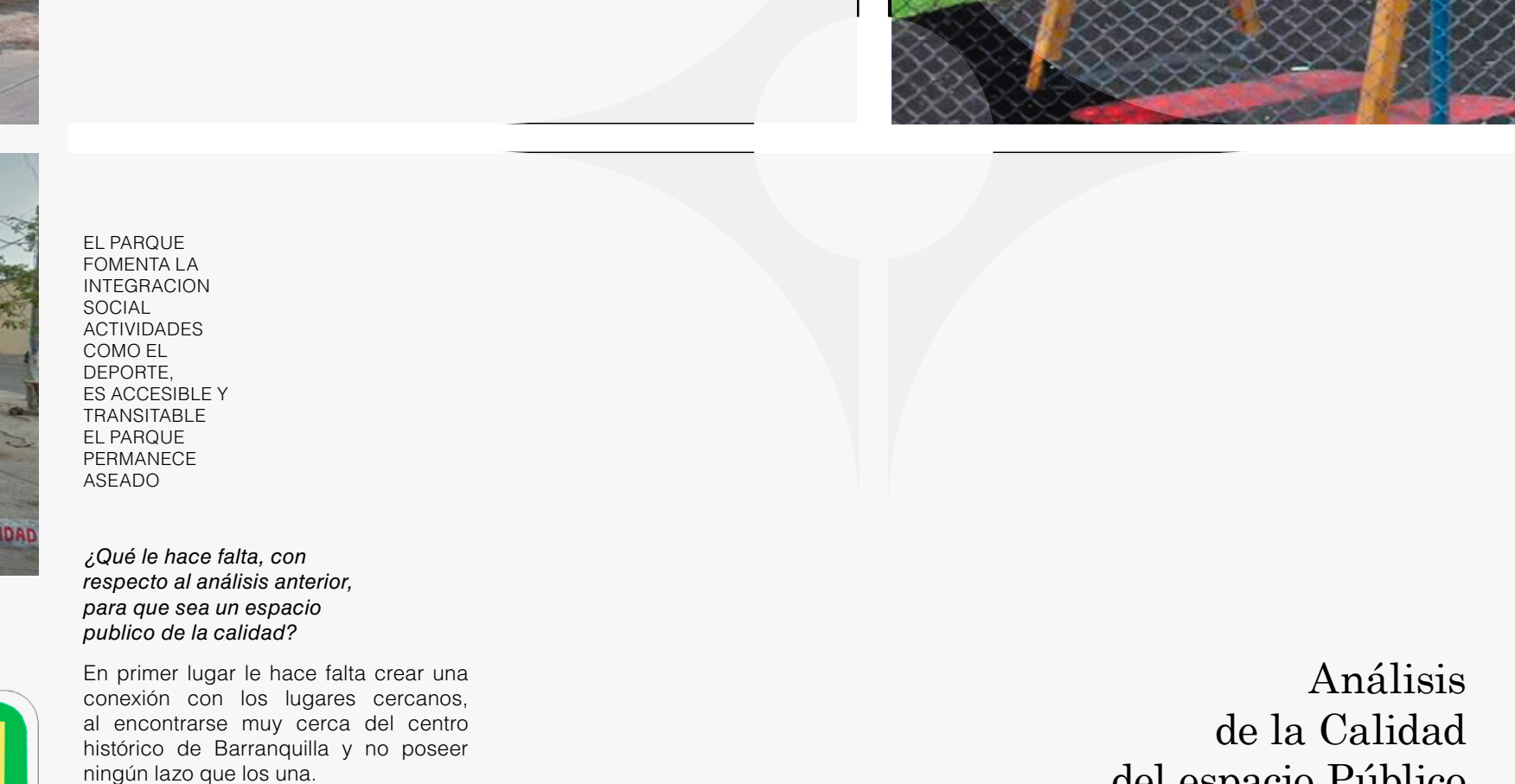

del espacio Público

Los titems coloreados son los que prevalecen de cierta
torme an el espacio, mientras que los que se encuentran
en blanco no existen inen l mismo

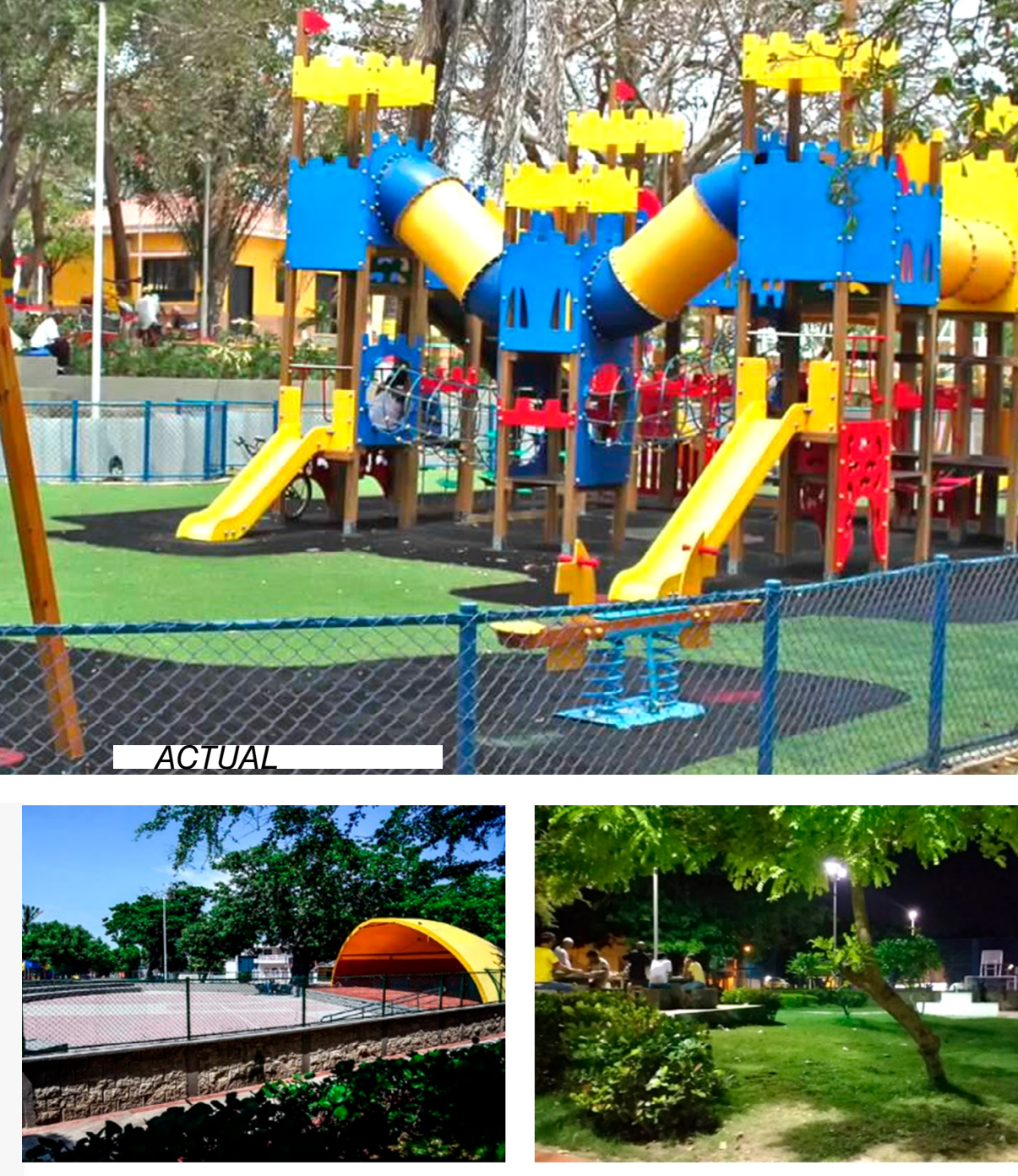

CONVERGENCIA

TRANSFORMACIÓN

El parque Almendra une a El parque Almendra fue uno
las comunidades del San Roque, de los escogidos por la alcaldía

Chiquinquiráy Atlántico en Barran-

y permitir una transformación en

espacio publico de calidad.
contrato para la transsormación de este espacio público fue dada el 2015 


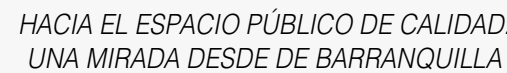

Por otro lado, el espacio público, es el espacio común que se comparte sin distinción de clases sociales o credos y que permite la interacción y la expresión libre, a traves del espacio publico se gener ciudad. Barranquilla, como Distrito Especial Industrial y Portuario, para el año 2014, poseía $0.83 \mathrm{~m}^{2} / \mathrm{hab}$. indicador que para la Organización Mundial de la Salud (OMS) y e Programa de Naciones Unidas para Inedo Ambiente (PNUMA, 2003), uran supería ser $15 \mathrm{~m}^{2}$ hat ublinim lianas y esquivas para esta urbe. plantearon para la ciudad que se Plan de Ordenamiento TerritorialP.OT y el Plan de Manejo Especia Protección-P.M.E.P. (Alcaldía de Barranquilla, 2012) es de $6.4 \mathrm{~m} /$ hab.; y a partir del 2014 se viene desarrollando estrategias de mejoramiento, embellecimiento adecuación a mediano y corto plazo de plazas, parques y en general de spacio público, para convertir a "I puerta de oro, en ciudad integral" Este estudio y analisis global de espacio público que se toma de ela, nos permite hacer comparay la eficiencia de ellos. Fig. 3. Infografía Fuente: elaborado a partir de las fichas "1
Parque Bellavista

LOCALIZACIÓN

Calle 72 con carrera 61

ANTES (2016)
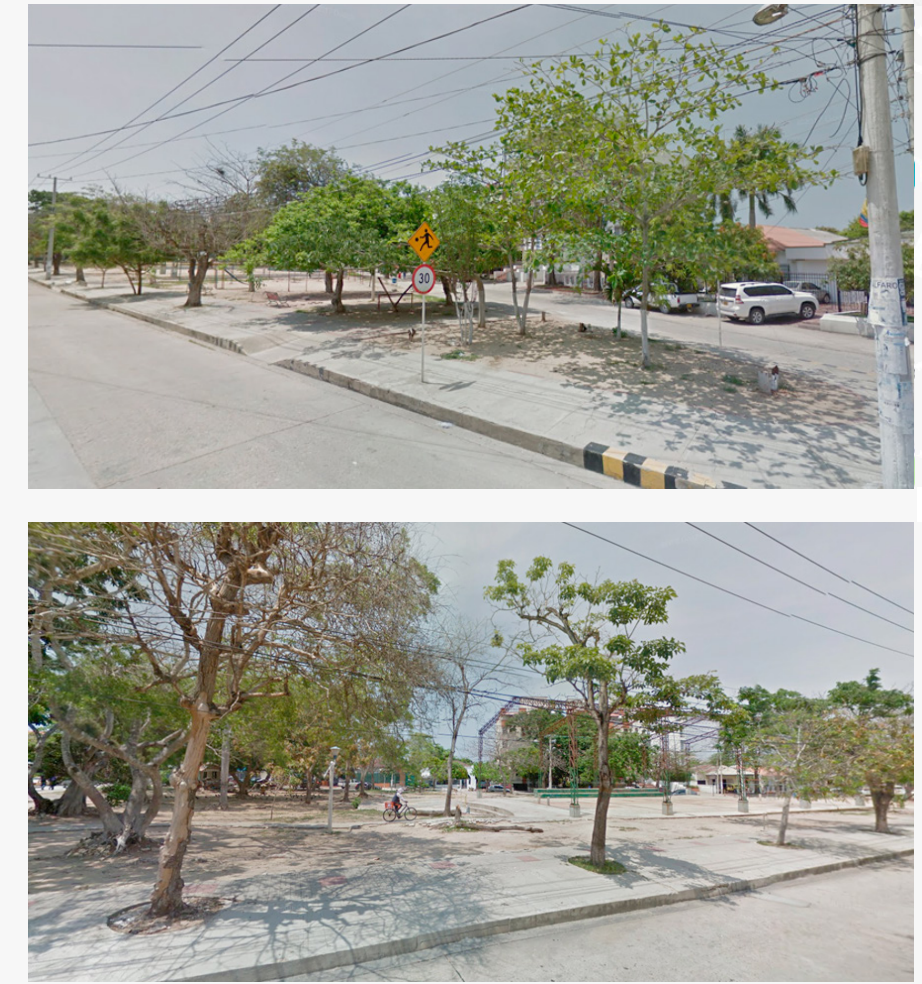

ZONIFICACIÓN

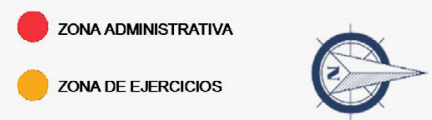

ZONA VERDE

zonanureos wiros

zomorporits

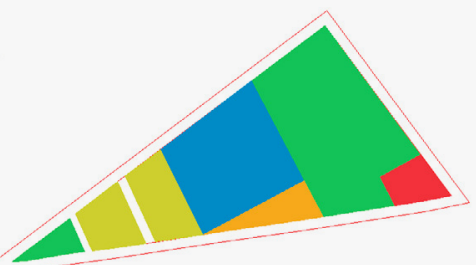

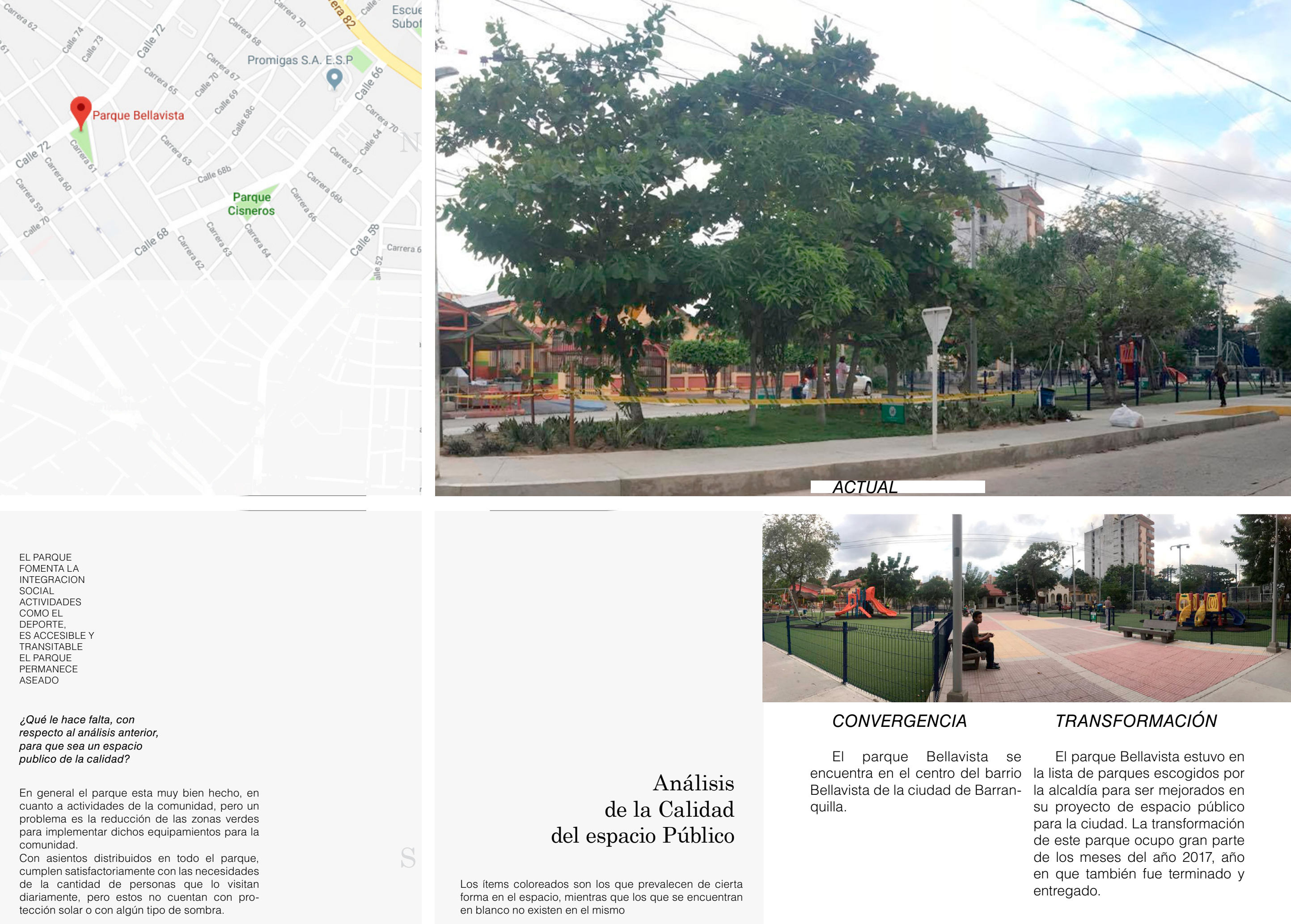




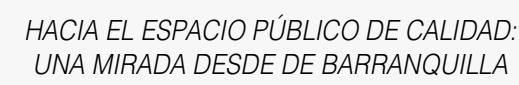

A pesar de que la lucha sigue siendo continua, al invertir en el mejoramiento de los espacios públicos, sucede algo paradójico; los entes gubernamentales han desarrollado tareas para reforzar y "meterle mano" a los espacios existentes, modificando desde su estructura, forma, funcionalidad, hasta llegar al punto de amoblarlos y convertirlos en nuevos escenarios. Pero, en algunos casos no hacen Pestudio de la población o necesidades de las comunidades, un de definir a ficiencia o calidad de desarrollo de este tipo de espacios han caído en el truco de diseños que discrepan de la realidad, al ser concebidos desde una computadora, alejados de la realidad y que suelen ser desestimado del poder que estos escenarios tienen en and page" de forma deliberada 0 abrupta.

Sin embargo en otros casos son sprios que expacios que ya existo que para un funcionamiento de calidad que pueda acomi a lo ciudadanía

Fig. 4. Infografía parque Euente: elabo
Parque La Placita del Valle

LOCALIZACIÓN

Esquina calle 70 con carrera $21 B$

ANTES (2014)
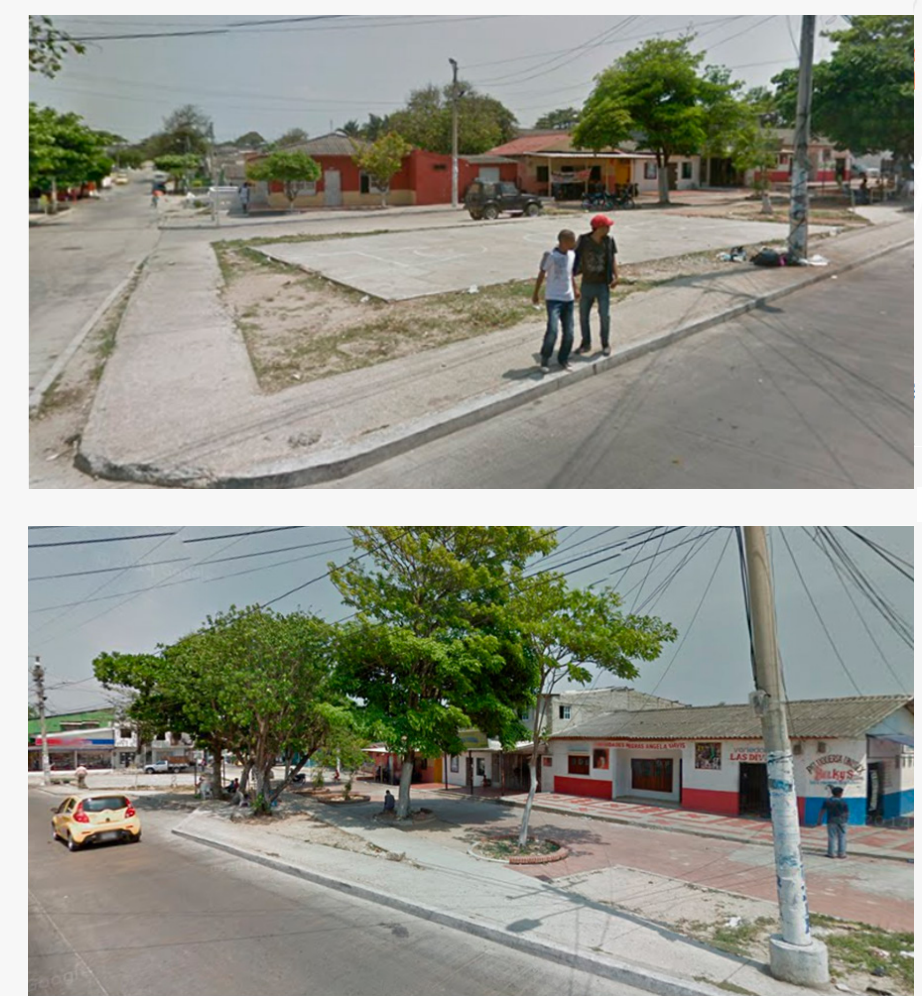

ZONIFICACIÓN

OZona verde ha)
Zona de ejercicicis
Zzona de Estancis
0

La casa del
agua purificada

Colegio Distritial La Salle

7 Colegio Distrital La Salle

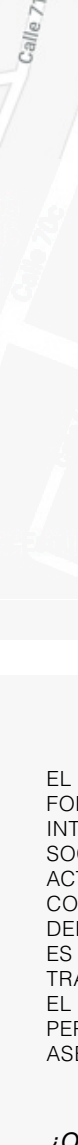

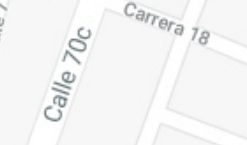

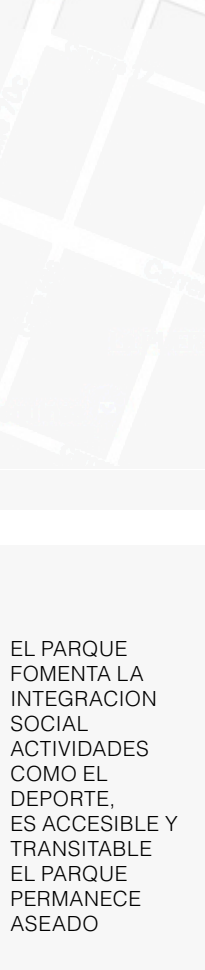

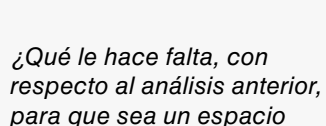

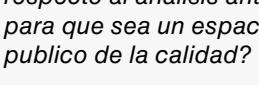

Principalmente algún cuerpo de seguridau
o equipos admininistrativos que brinden mas o equipos adminisitrativos que brinden mas
connianza a los usuarios la horra de habitarlo,
estas inseguridadus son debido a los muchos

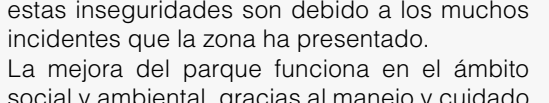
$=$

Parque 


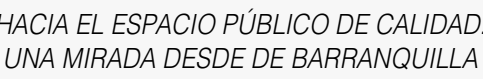

pero que al transformarlos desde sus componentes, su forma, funcionalidad e incluso agregando nuevas zonas, se convierten en escenarios de interacción social, que piensan en las comunidad con movilidad reducida, en la diversidad de usuarios y en actividades BioSaludables o recreación, sin dejar de lado la arborización y el mejoamiento del medio ambiente. Un Claro ejemplo de este es el parque Virgen del Carmen (Ver Fig. 6) en estudiar, diseñar y vivir el espacio público, y en este caso especia donde las dimensiones del predio tan significativas a comblico no son otros que tienen mayor extensión de tierra.

Pero más allá de esto, el deficiente estado del espacio público es inferior a la cantidad de espacios públicos efectivos (parques, plazas, plazuelas, zonas verdes, plazoletas, etc.), de calidad que se tiene en la ciudad. Pero, lo que si lo sobrepasa es lo insuficiente de las cifras que se registran de ellos. Es alli donde se toca la contraposición de la calidad versus la cantidad, el espacio público de Barranquilla.

Fig. 5. Infografía

Euente: elaborado a partir de es fichas " 1 y the
Parque Los Andes

LOCALIZACIÓN

Calle 63 con carrera 26

ANTES (2014)
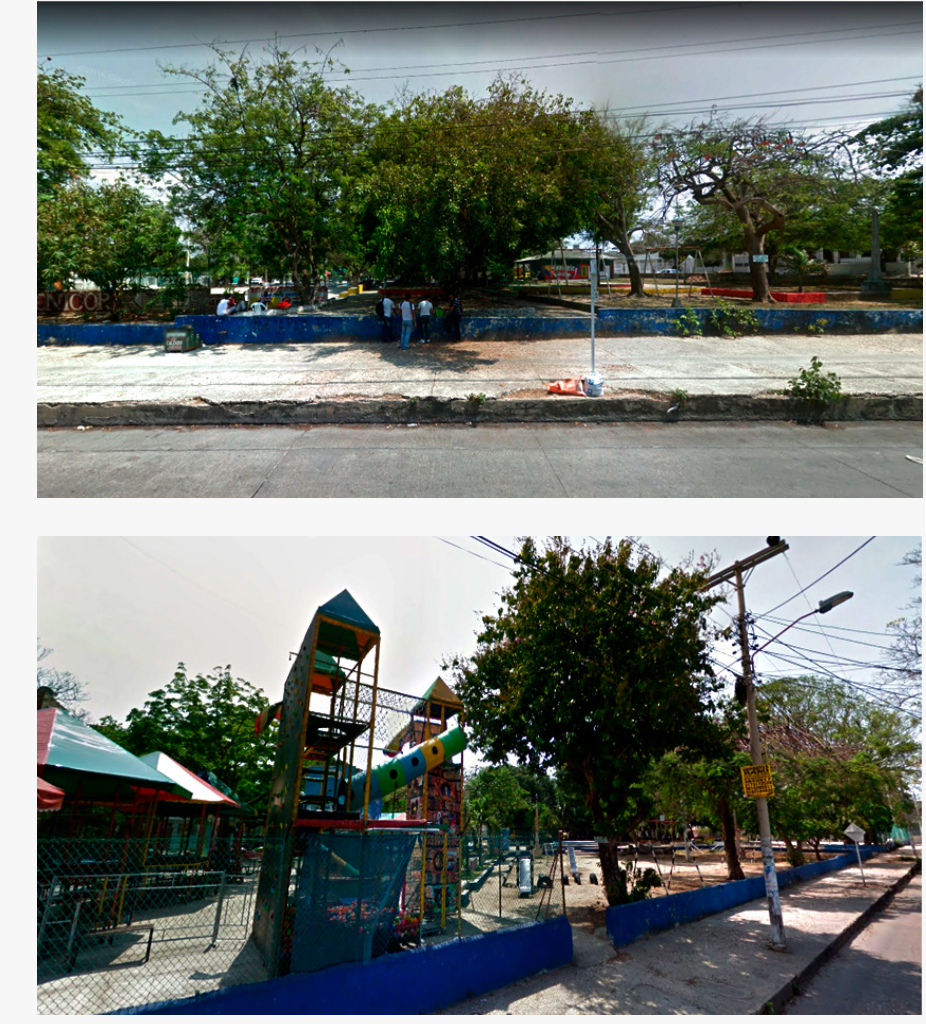

ZONIFICACIÓN

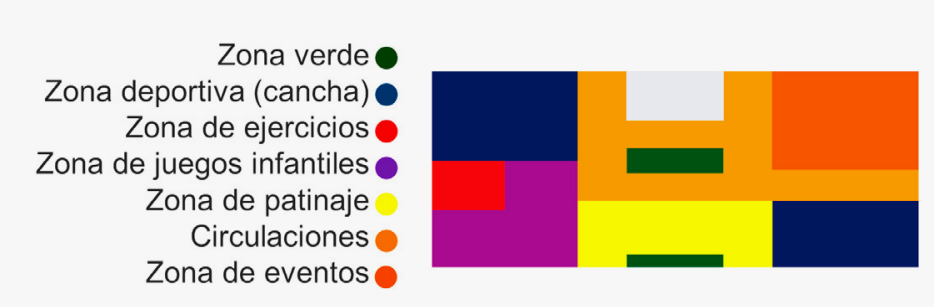

Comuneros of carer 29

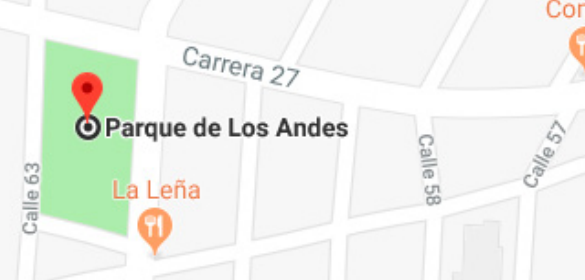
n.

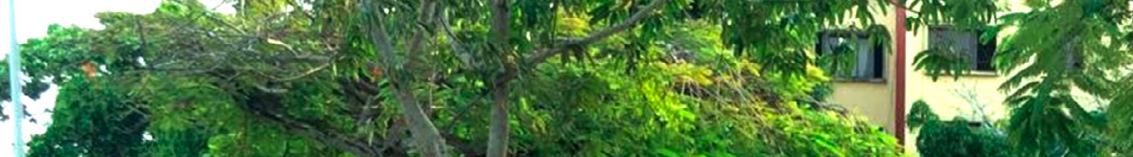

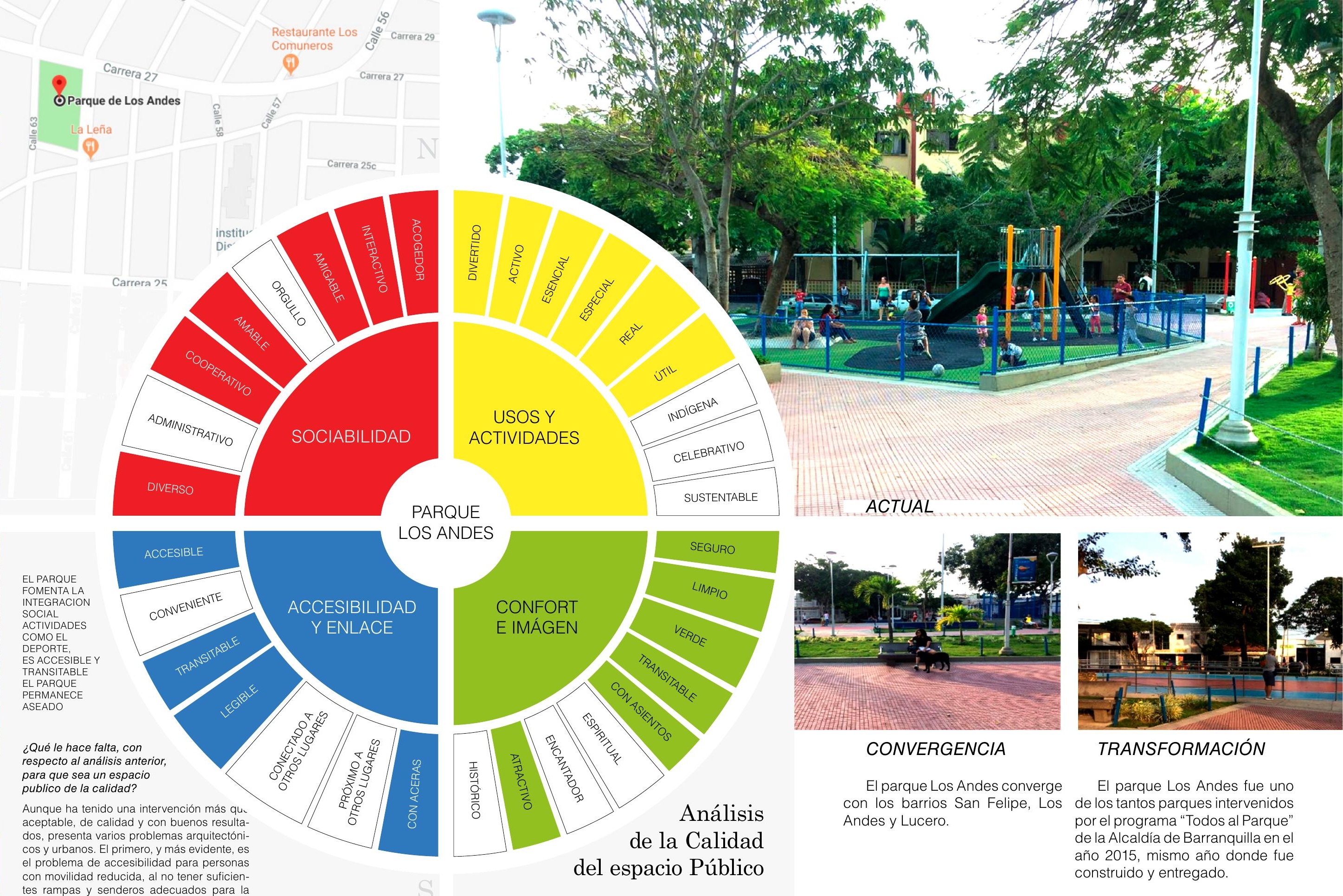

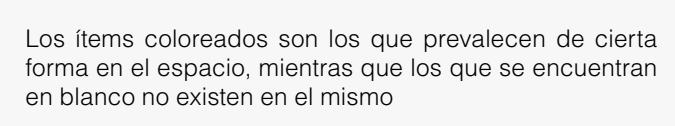

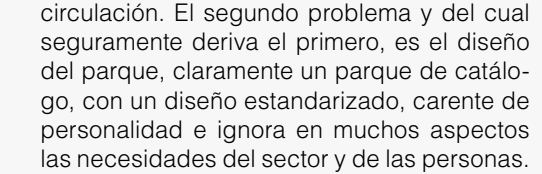


HACIA ELESPACIO PUBDLCODE CALLDAD
UNA MIRADA AESDE DE BAPRANQULLAA

Además de la fuerte crítica sobre la mayoría de los espacios evaluados, sobre todo en el tema de materialidad, pues, aunque la sostenibilidad es un término que esta mezclado en cada una de las cosas que se ve a diario, el enfoque ecologico y ambiental es muy minimo. Especificamente en algunas de las zonas verdes de los parques, que eran conformadas por césped y tierra, es común que se encuentren ahora caucho y grama la mayora por no decir que, en la mayoria, por no decir todas, las por fibras sintéticas que evocan la grama evitando colocar una real grama, evtan do colocar una rea; es una de las zonas más grandes de todo el parque (Ver Fig. 2). De estos casos se desconoce ustificación exacta de las razones porque se disponen en estas áreas unas materias que no son "reales" ecológicamente no brindan mucha sostenibilidad de los espacios a comparación de la grama natura real. Podriamos pensar que el uso de la grama sintética se prevé para que los usuarios, y sobre todo los niños, puedan transitar librementendo la que sid de estar real se deteriora y así se evitaría

Fig. 6. Infografía parque La Virgen del Carmen.
Parque La Virgen del Carmen

LOCALIZACIÓN

Calle 47 \#1C Sur-2a 1CSur

ANTES (2016)

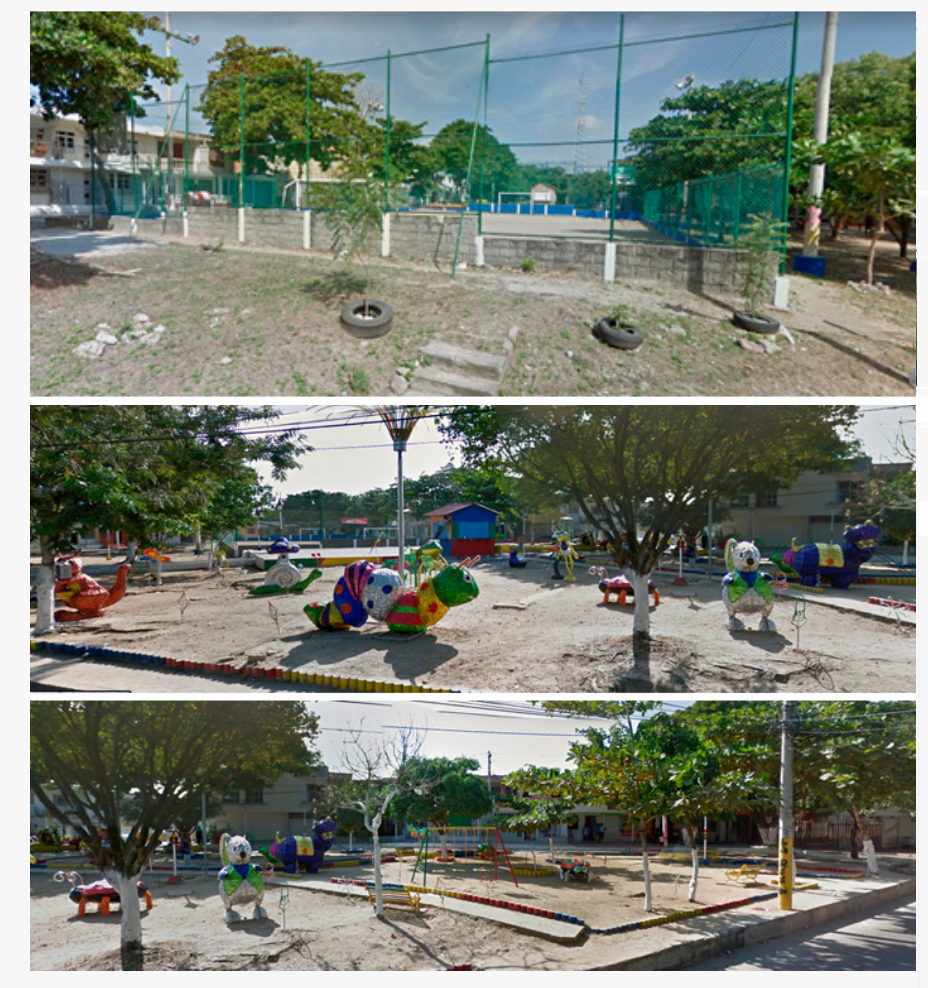

ZONIFICACIÓN

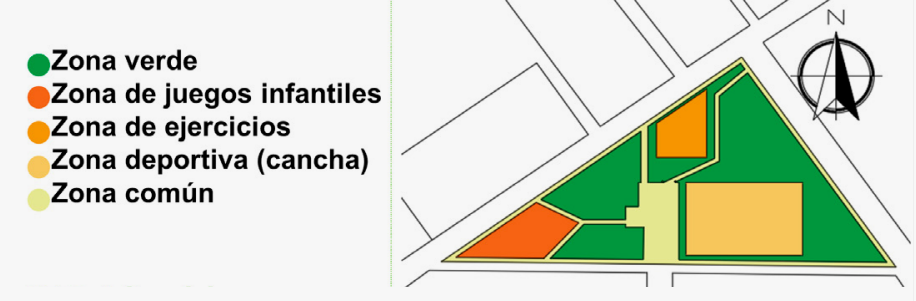

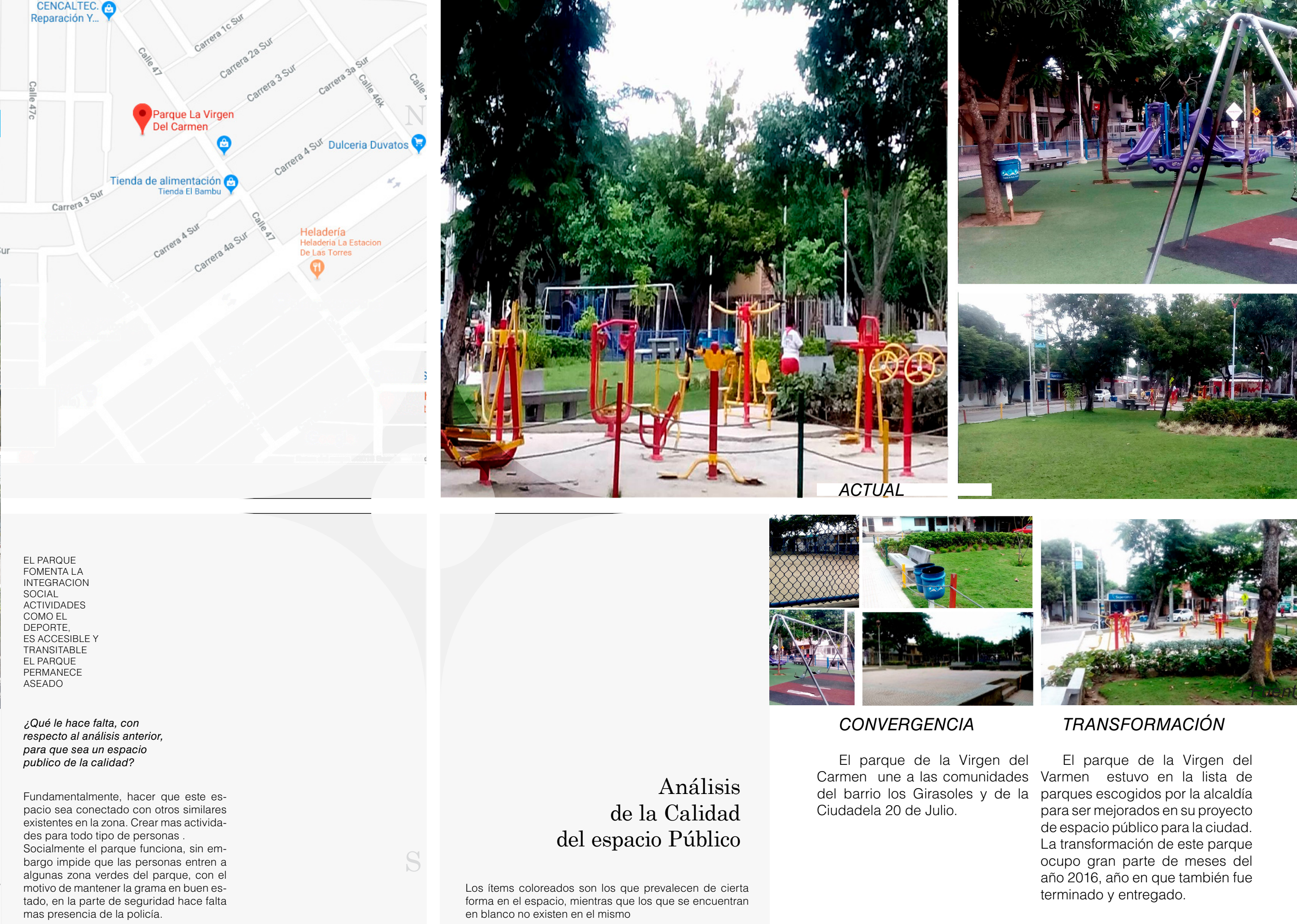




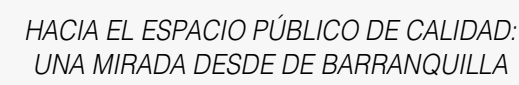

el mantenimiento de las mismas, y esto se sostiene al ver que el $50 \%$ de las zonas verdes de un parque son reales $y / 0$ naturales, $y$ el otro $50 \%$ es efectivamente artificial; esta última esta ubicada cerca a las áreas de juego donde notoriamente el público transita más

Tras la intervención de la alcaldía con su plan de mejoramiento, han mermado muchos problemas sociales dentro de la ciudad, pues, al econtrarse estos parques en ma ción no sudir a ellos en modo integración, era muy fácil observar que dentro de estos mismos

114 otras actividades muy diferentes Otras actividades muy diferentes públicos, como tristemente ocurría en La placita del Valle (Ver Fig. 4). Por ejemplo; la delincuencia, el vandalismo, el consumo y el expendio de drogas e incluso en muchos casos su utilización como basureros púbicos. Entonces se podría decir que, a pesar de la poca calidad Barranquilla en terminos de espacio público efectivo presenta una buena calidad, pero el camino aun es largo y se debe seguir apostando en la inversion de mejores escenarios, pro de la comunidad.

$$
\text { Fig. 7. Infografía parque }
$$
Las Americas.
Parque Las Américas

LOCALIZACIÓN

Calle 64 entre carreras 49 y 50

ANTES (2014)
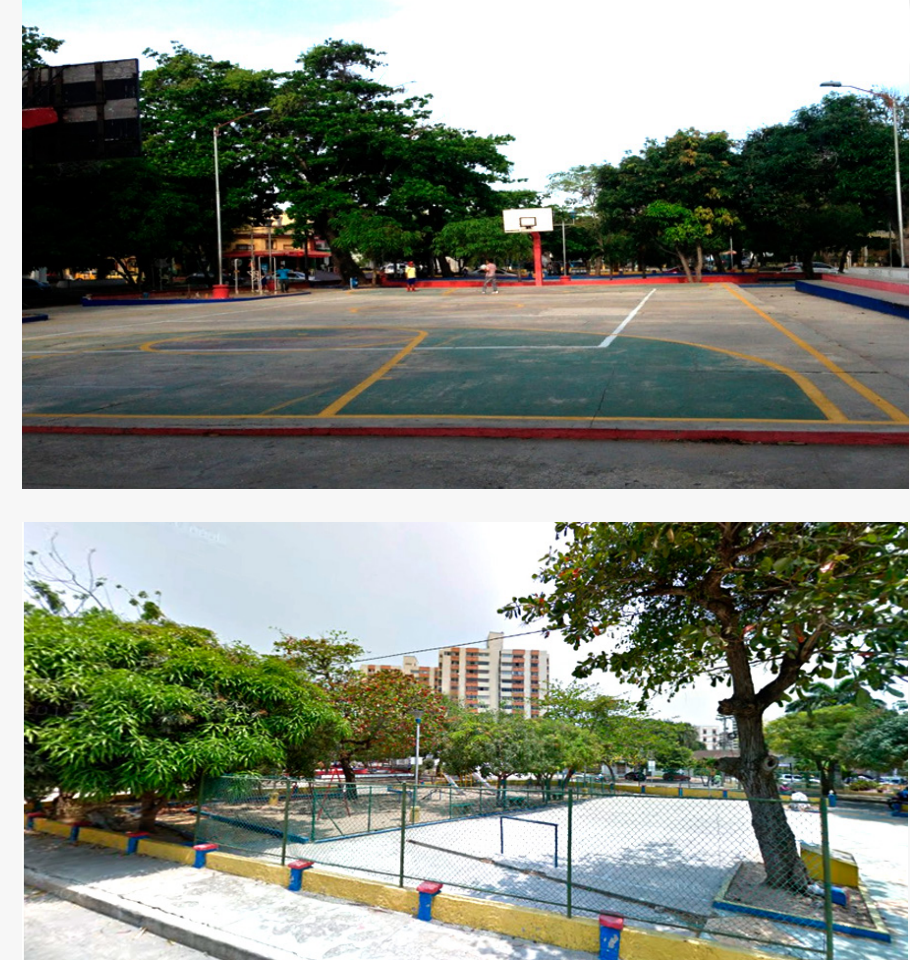

ZONIFICACIÓN

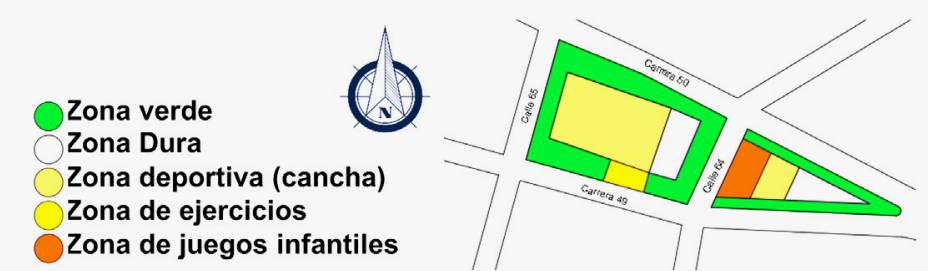

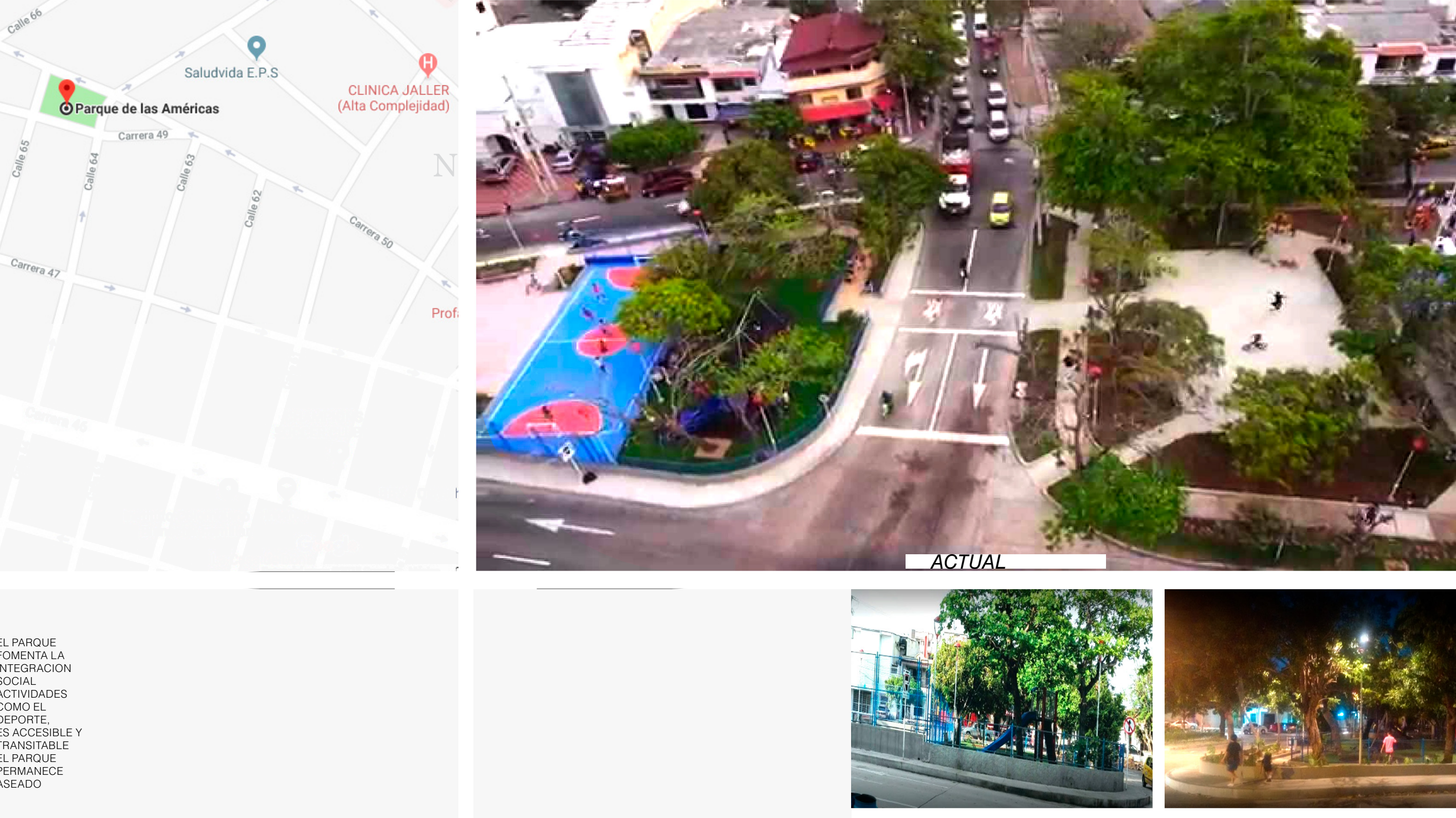

CONVERGENCIA

TRANSFORMACIÓN
Análisis de la Calidad del espacio Público El parque Las Américas une a
las comunidades del barrio Boston, El parque Las Américas estuvo Lo que Ie fatta al parque para que sea un

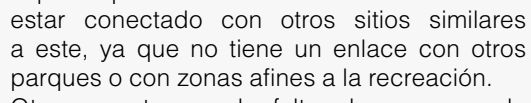

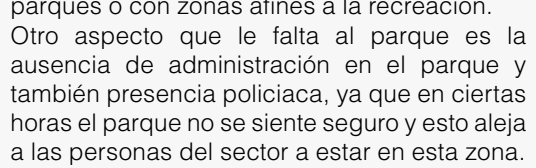
por la alcaldía para ser mejorados para la ciudad. El parque muestra cambio generales, ya que tien una mejor presentacion y un redla inclusión de espacios como la
zona del gimnasio. 


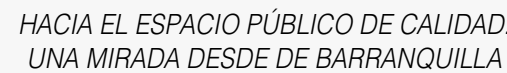

Ahora bien, al estudiar y analizar a calidad del espacio público en la ciudad a través de la metodología anteriormente mencionada y además conocer las definiciones o conceptos que tienen muchas personas sobre los escenarios de
indole público en la ciudad, donde las personas reconocen estos lugares como aquellos que posibilitan la interacción, las dinámicas sociales y ante todo el desarrollo libre de cada individuo: pero en muchas ocasiones todo este potencial no es como la insuficiencia por factores cono la insuifiencia en equipao el estado en el cual se encuentran. El desconocimiento de lo que se requiere para generar espacio
público de calidad es una de público de calidad es una de las área de influencia que lo obliga a ser único, subir y caracterizar sus necesidades y hábitos, debido que a fin de cuentas son ellos quienes los vivirán. Con esta dinámica se fortalece el conocimiento y la experiencia en la participación de estudios procesos en comunidades diversas apreciando lo valioso de estudiar e espacio público y que otros aprecien esto y den su opinión, pues somos todos los que construimos

Fig. 8. Infografía

Fuente: elaborado a partirir de las fichas "1 1 t t2
Parque Cisneros

LOCALIZACIÓN

Calle 68 entre carreras 64 y 65

ANTES (2016)
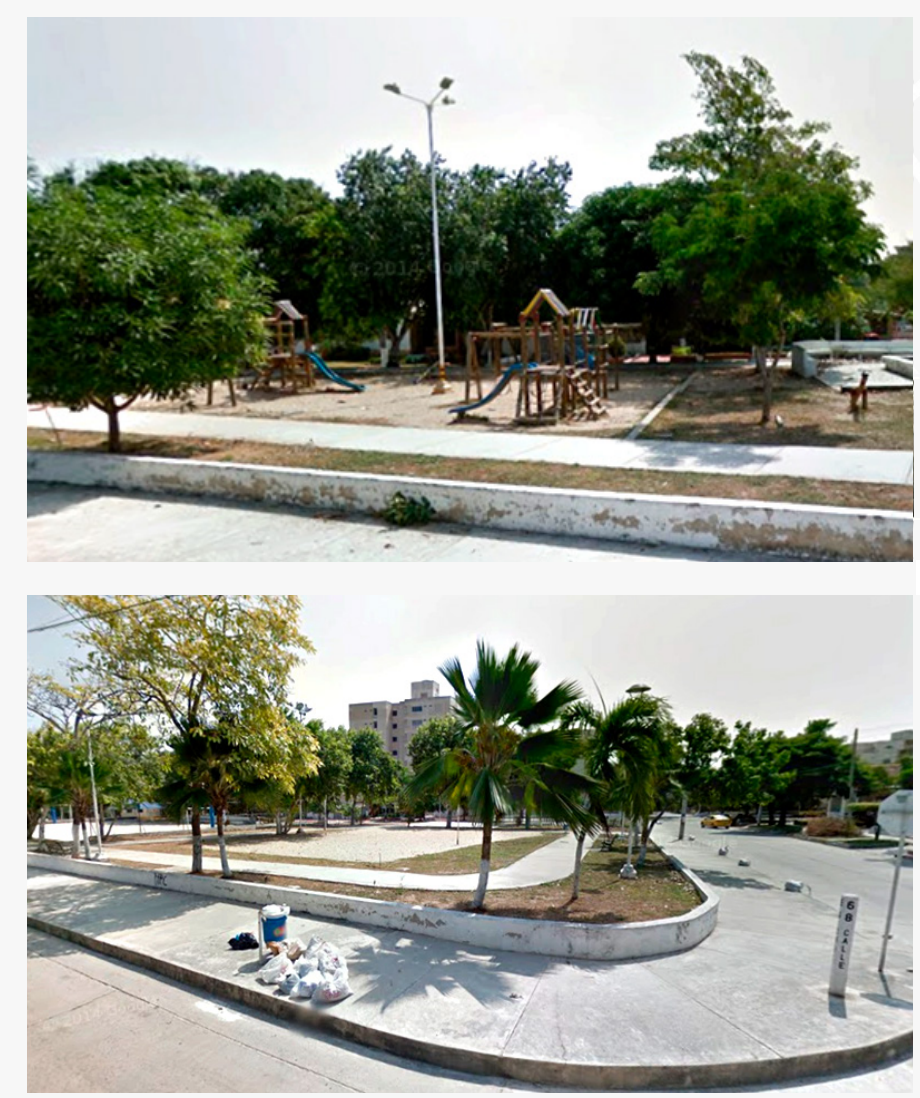

ZONIFICACIÓN

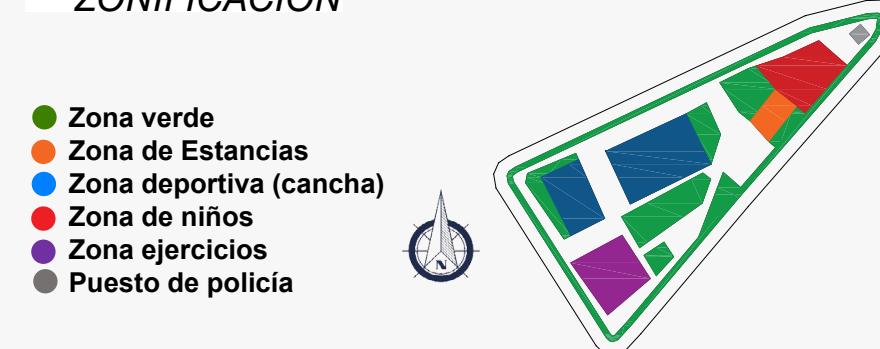

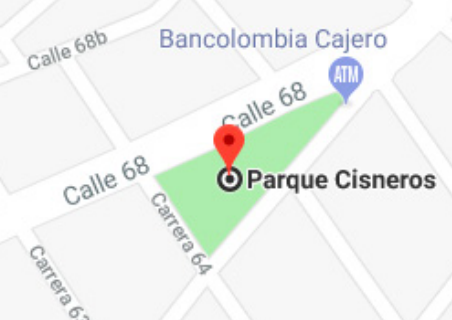

si

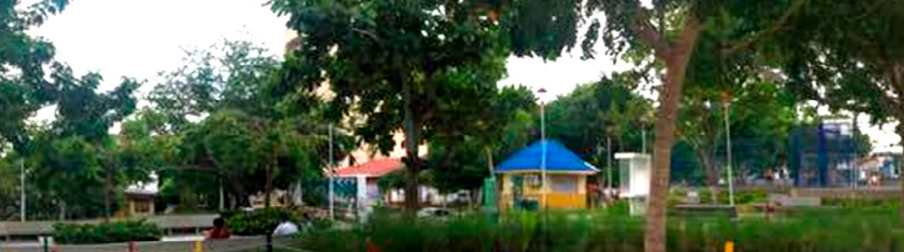

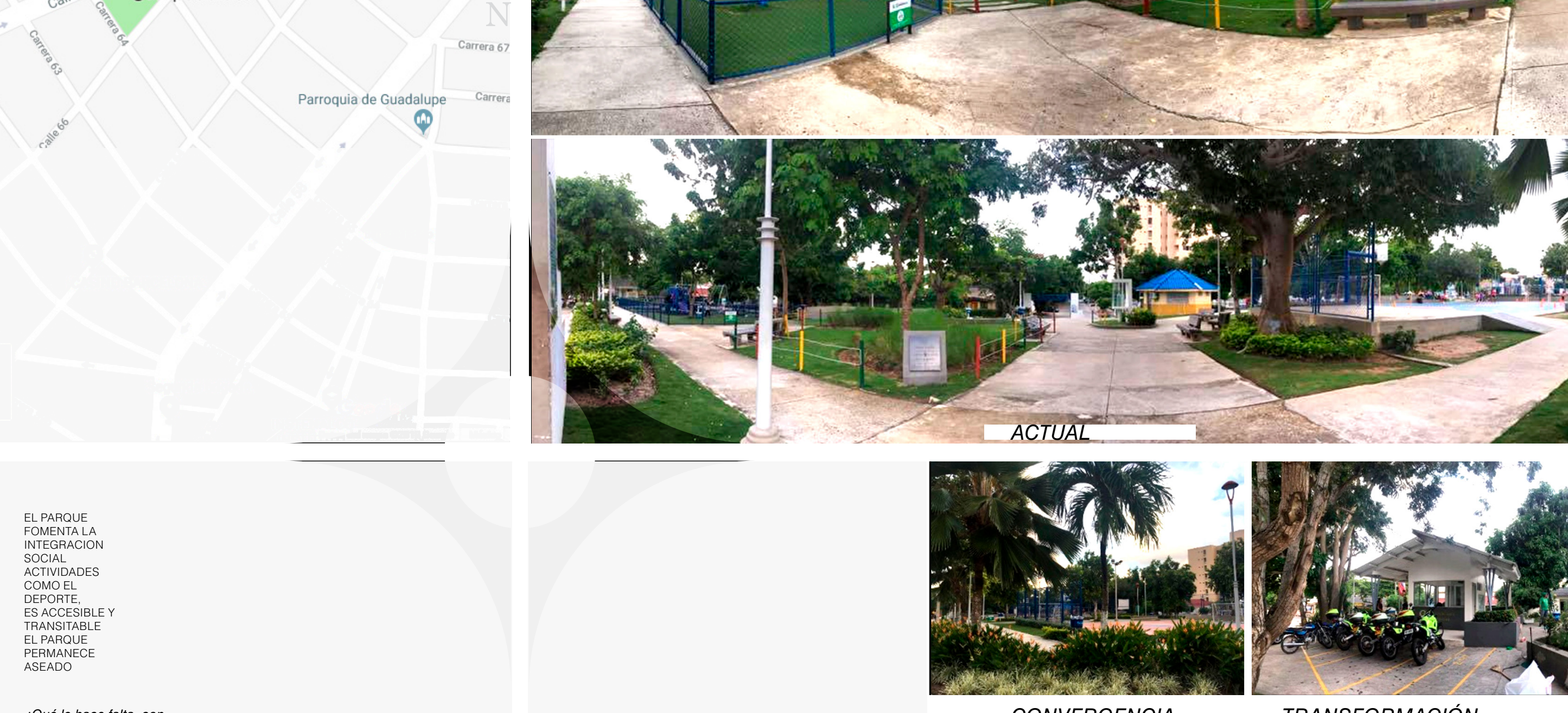
CONVERGENCIA

TRANSFORMACIÓN

Análisis de la Calidad del espacio Público

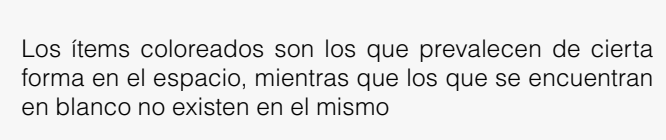

El parque Cisneros une a las
comunidades del barrio Santa Ana
Y Bellavista

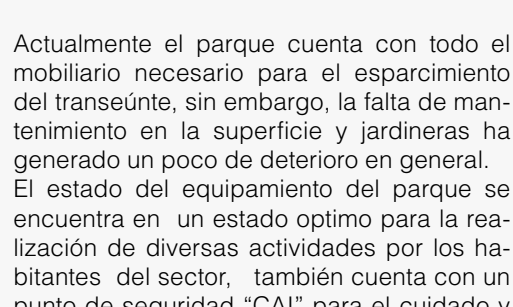
bituntes del sector, también cuenta con un
punto de seguridad "CAll para el cuidada y
protección de la localidad

\section{El parque Cisneros estuvo en}

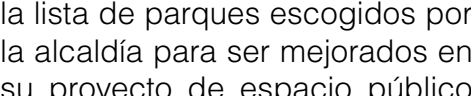
su proyecto de espacio pubilico
para la ciudadad. La transtormación de este parcue ocupo gran parte de meses del año 2016, año en gado. 


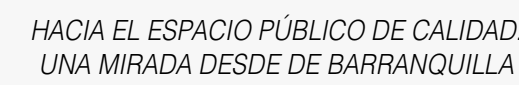

Conclusiones

A partir del espacio público nace la ciudad y este no es un espacio es la relación social, la floración las diversas dinámicas que componen las comunidades de las urbes; esta fue una de las conclusiones que logramos con el anallisis y estudio del espacio público de Barranquilla los procesos que se llevan a cabo en el, de la calliad de los espacios con los que se cuenta y la crítica denunclas que se tienen de ellos. y plazas cuestionados a nivel de diseño, funcionalidady materialidad siguiente manera: Son proyectos que en algunos casos no obedecen a un estudio análisis de las comunidades para de esta forma lograr un diseño que los satisfaga y se logre captar la esencia o dinamicas de las comuidades a quienes impacta. Y esto se debe en parte a que es poca la socializacion de estos procesos conlas comunidades que los utiliza. Suelen ser parques genéricos que aunque aportan una mejora en los sectores no tienen una relación personas del sectris vivir de las patrón en estos parques la utilización

Fig. 9. Infografía Euente: elebordo a partir deños.
LOCALIZACIÓN

Carrera $40^{a} 1$ con calle 91

ANTES (2015)
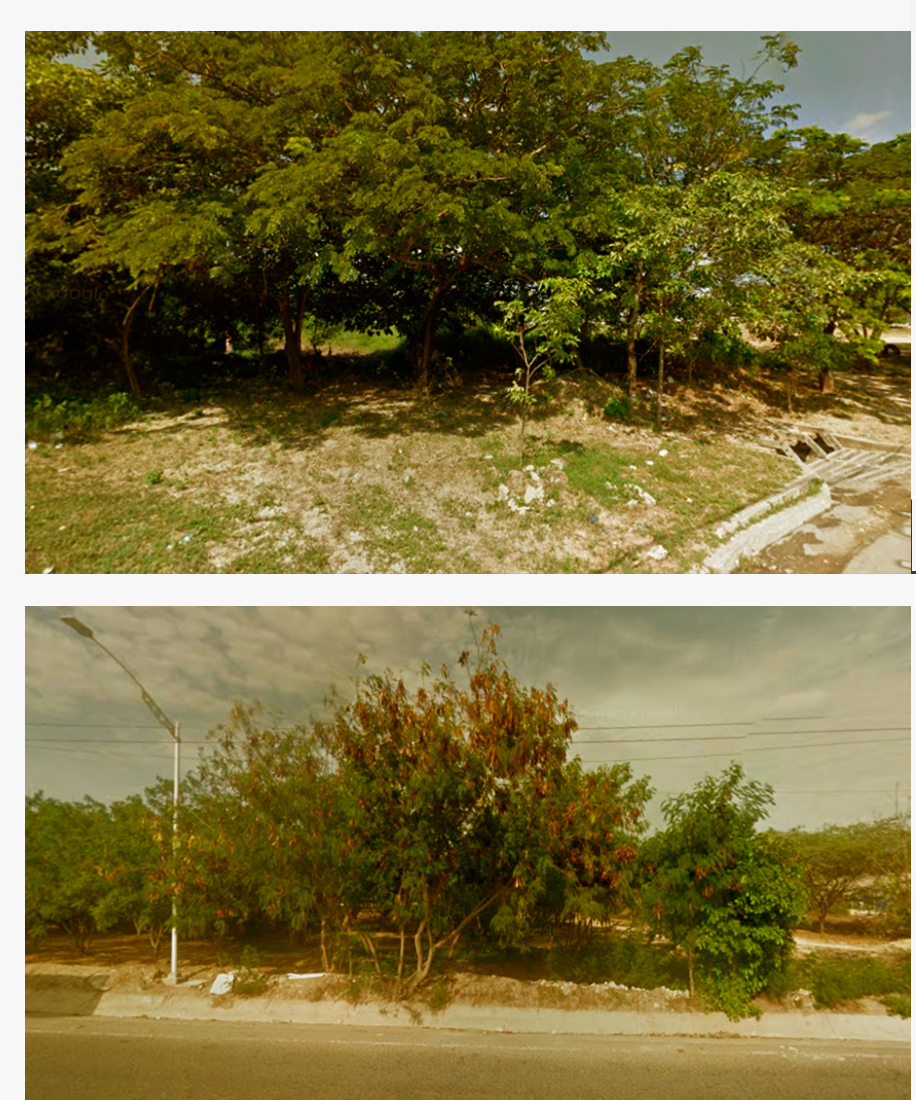

ZONIFICACIÓN

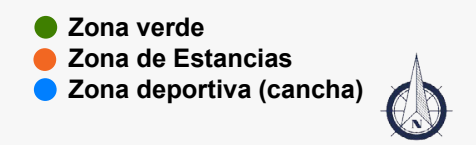

Conjunto Residencial
Portales Del Campo
Carrera 40a1

Carrera 40a 9 Parque De Los Sueños

(7) Gazel Campo Alegre
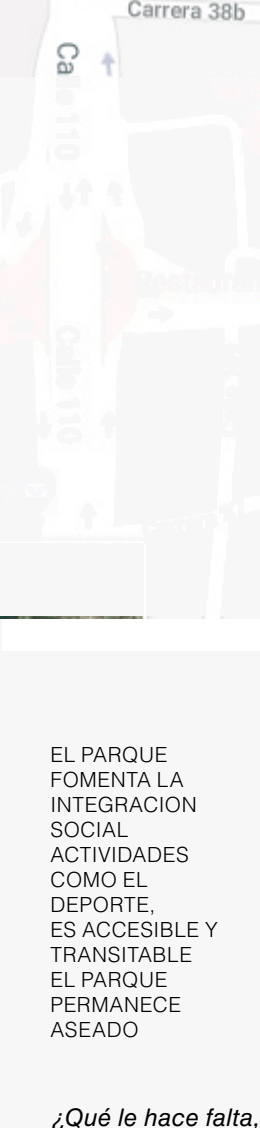

¿Qué le hace falta, con
respecto a a analisis anter

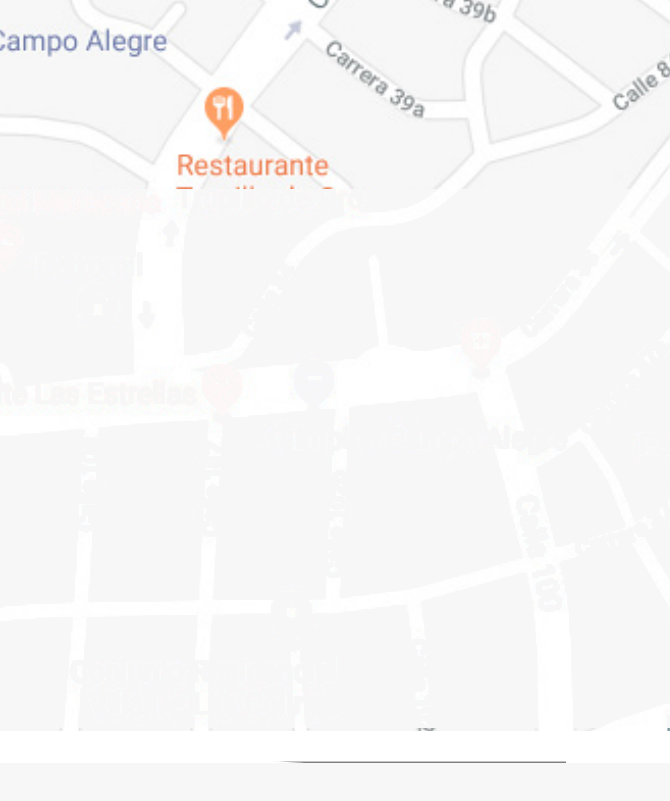

PARQUE
DE LOS
SUENOS

USOS Y

ACTIVIDADES

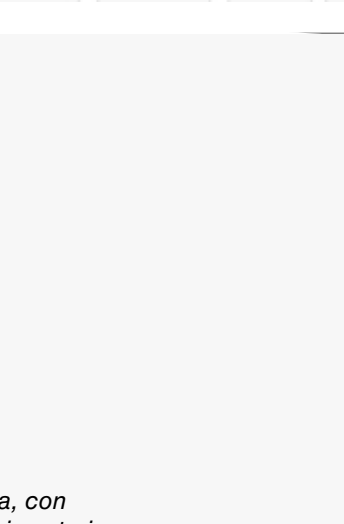

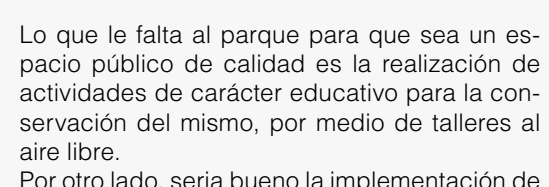

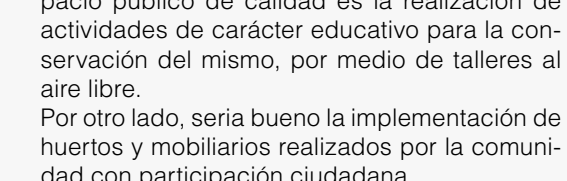

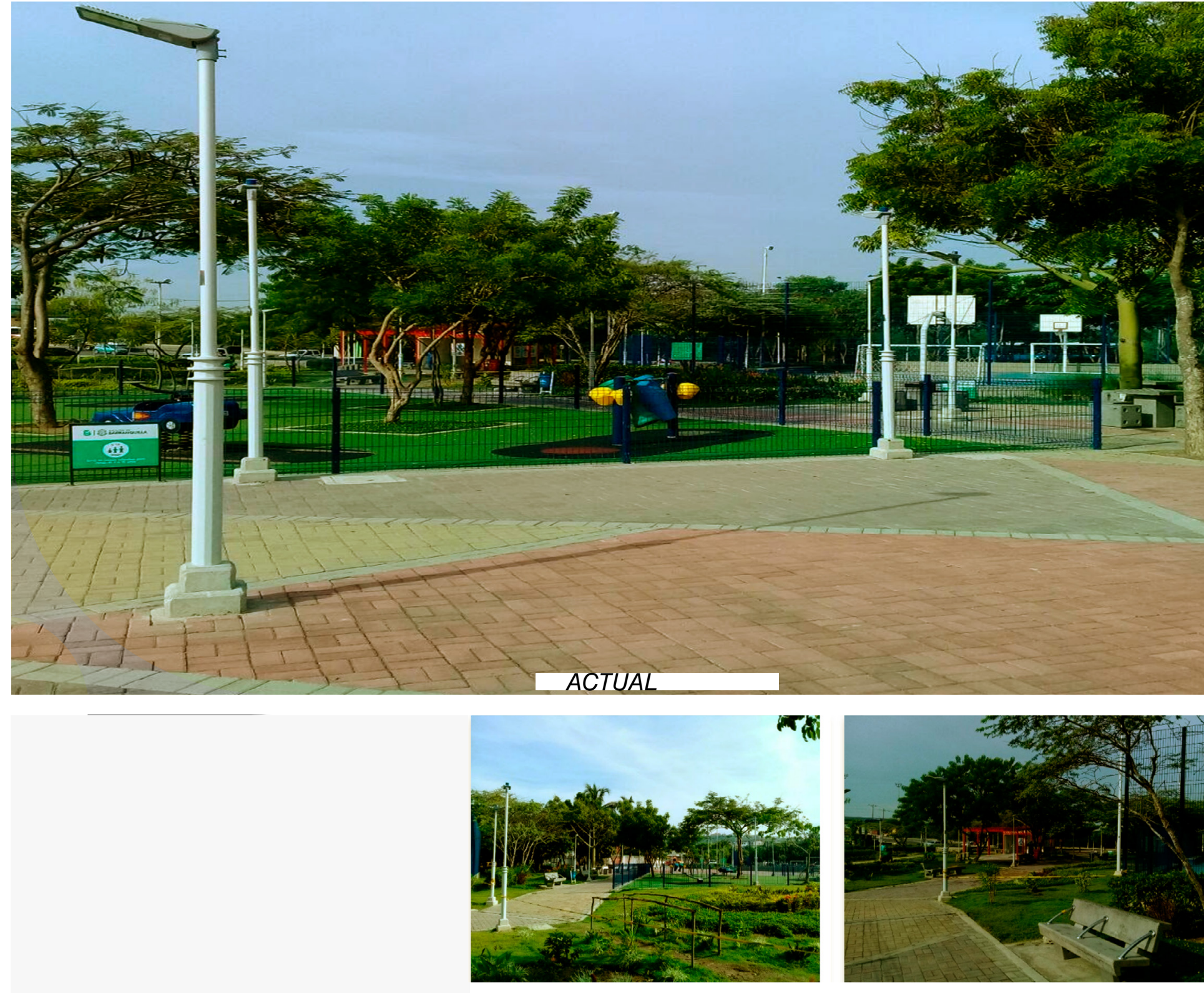

TRANSFORMACIÓN

Análisis de la Calidad del espacio Público

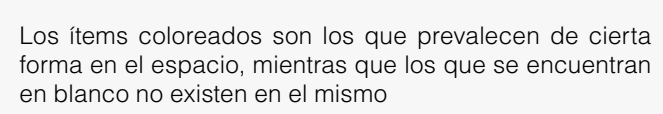

El parque de los Sueños
concentra la comunidad del barrio

El parque entro al programa
de rehabilitación de parques de la

de Campo Alegre, el cual a su vez ciudad, dándole a este una trans-

espacios a los barrios colindantes

este.

su anterior estructura carecía de
muchos espacios para la inter-
acción de los habitantes del sector. 


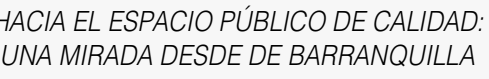

de alfombras verdes que no aportan áreas de vegetación reales, en las zonas de recreación. En lo material, los diseños y colores que se escogen, cabe resaltar no son de mala calidad, pero si que afectan a la calidad y eficiencia del espacio público.

Por eso resaltamos que el llevar un seguimiento de espacios urbanos se convierte en una ventaja, ya que es ani donde puede apreciarse el progreso o el retraso que este ha estudiantes de Arquitectura intervenir de mara é. No obtanto tras dicho estudio se pueden hacer particularmente las siguientes apreciaciones:

- La Placita del Valle se convirtió en un nodo para los habitantes que fundaron el barrio de tal como San Felipe y Nueva Cos conia. En Felpe yueva un proceso de rehabilitación, un proceso de rehabilitación este pequeño espacio urbano lograron adaptarse a las actividades de la comunidad, dando beneficios a varios aspectos tales como el confort, la seguridad, el entretenimiento y la comunicación.

Fig. 10. Infografía parque La Cumbre.
Parque La Cumbre

LOCALIZACIÓN

Calle 87 con carrera $42 E$

ANTES (2017)
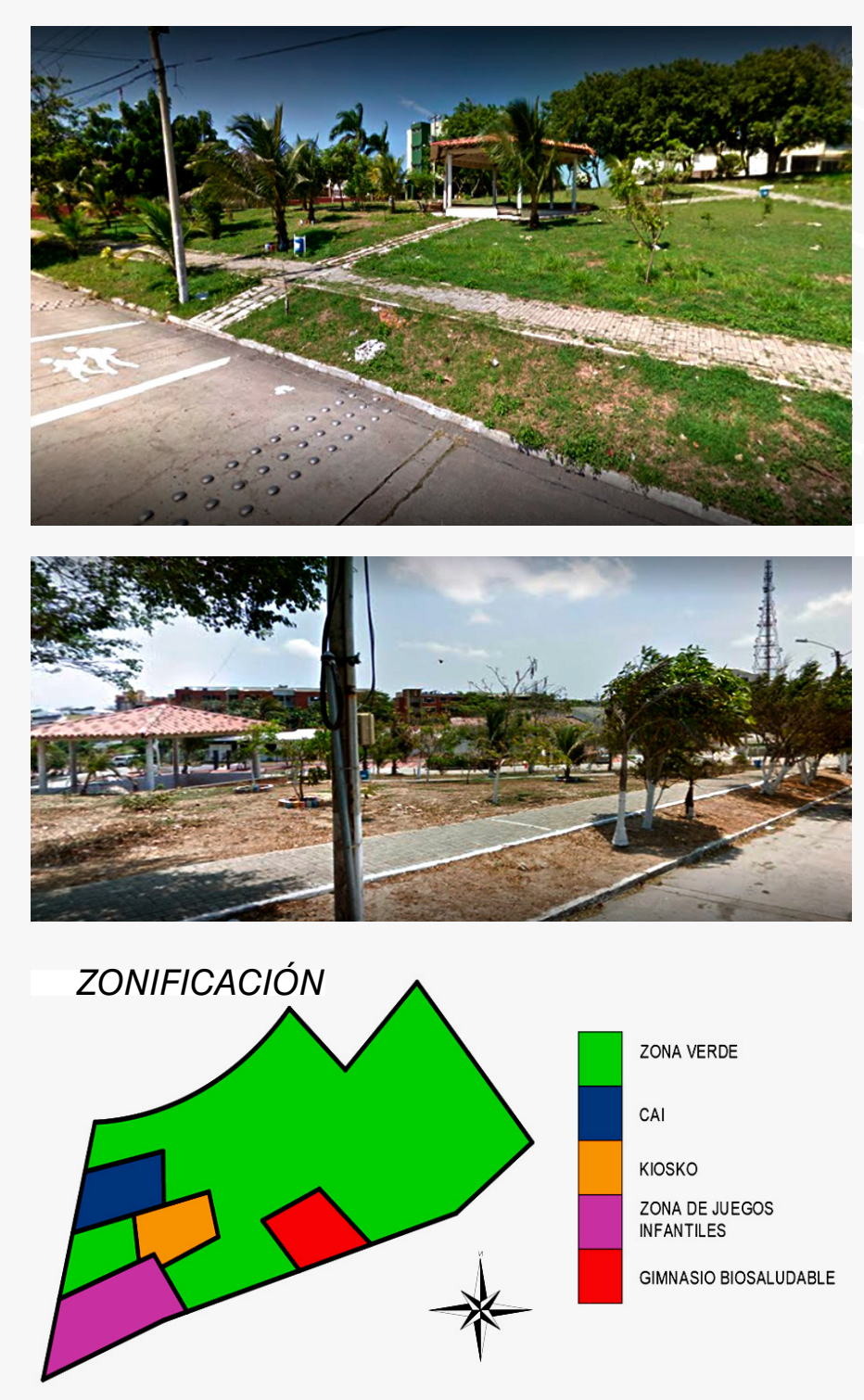

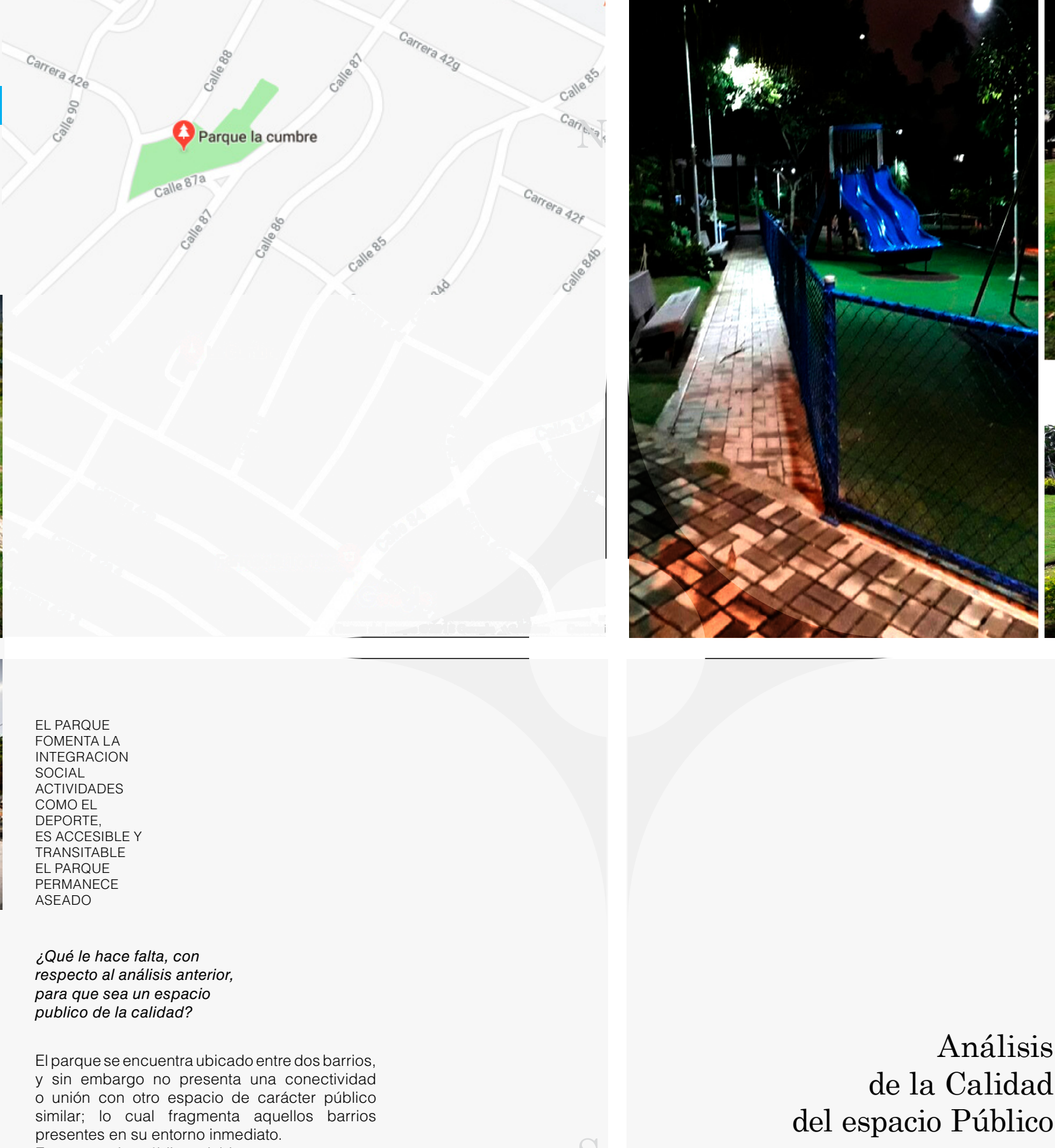

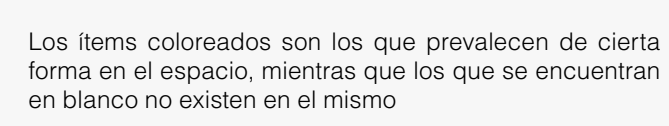

国.

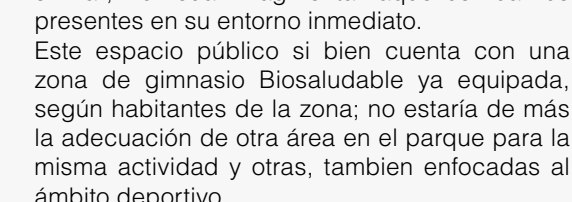

de la Calidad

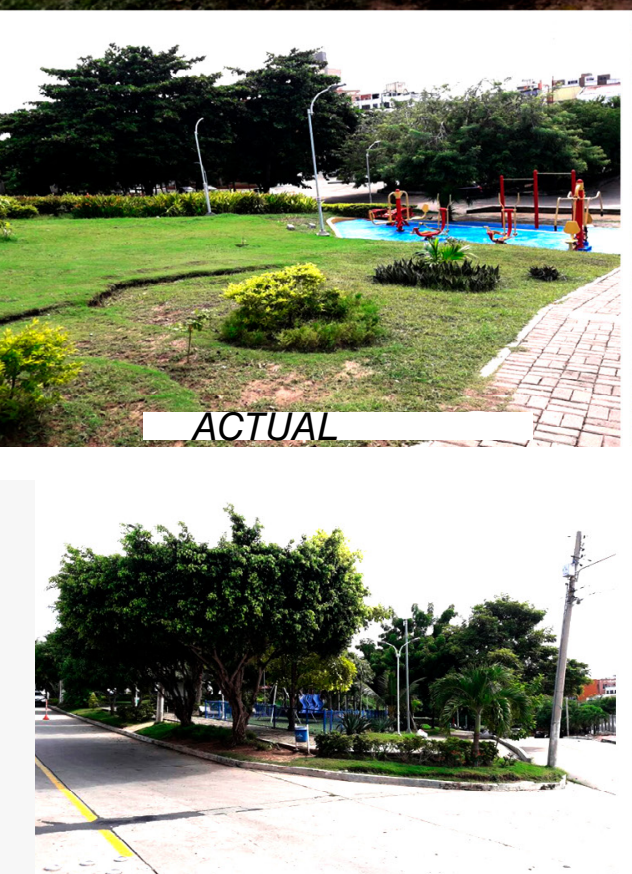

CONVERGENCIA

El parque se encuentra al servicio
de dos comunidades, entre los barrios de dos comunidades, entre los barrios
La Campiña y Los Alpes. A la fecha, gracias a la recupera-
ción de $3.832 \mathrm{~m}^{2}$ para el lisfrute de la
comunidad, los habitantes del sector comunidad, los habitantes del sector lograron disfrutar de zon
muestra en la zonificación. 


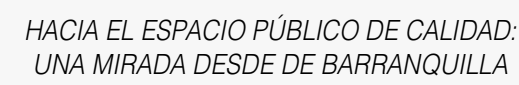

- El parque San Marino al ser intervenido por el plan de la alcaldía activó positivamente la zona; anteriormente la comunidad no visitaba al parque por miedo y por la inseguridad que en este se percibia. Hoy por hoy las habitantes, de todas las edades, del barrio San Marino, San salvador y la Floresta se convergen en este parque hasta altas horas de la noche gracias la inseguridad se mitigóc casi en un 100\%

- En los parques Cisneros y Bellavista la implementación de zonas de ejercicio fue un total exito, en la medida en que estas provocaron un incremento en el inters en la población adultomayor de la comunidad para lo largo del día así no solamente fuesen niños y ióvenes al

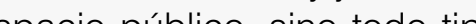
de usuarios en general.
Parque Cristo Rey

\section{LOCALIZACIÓN}

Esquina carrera $21 B$ con calle 52

ANTES (2014)
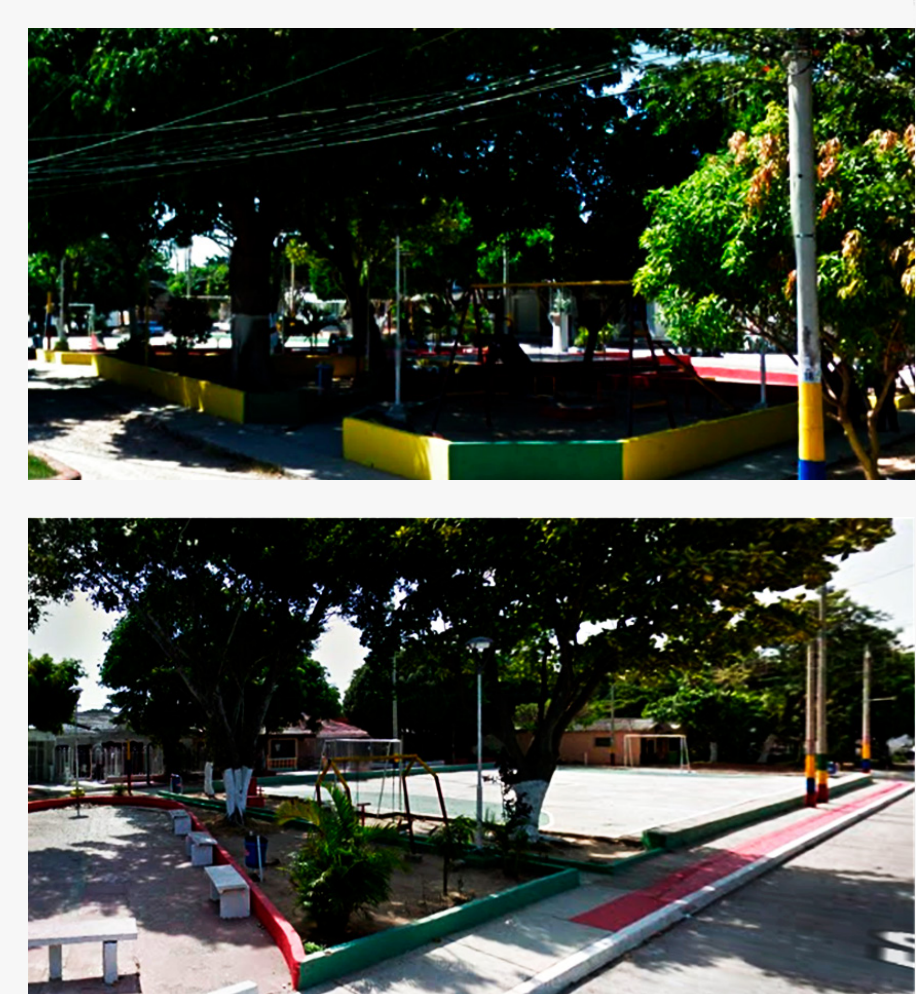

ZONIFICACIÓN

Zona verde Zona de Estancias

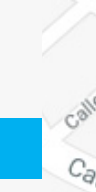

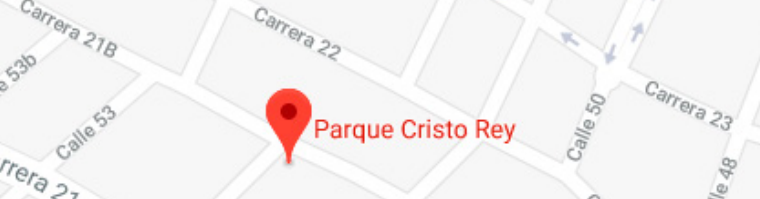

tho

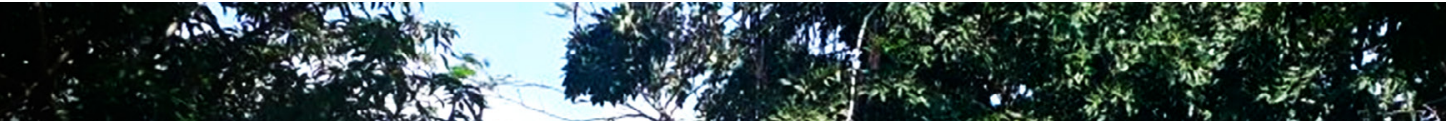

\section{Pobarque El Carmen
Melendez}

$\Theta$

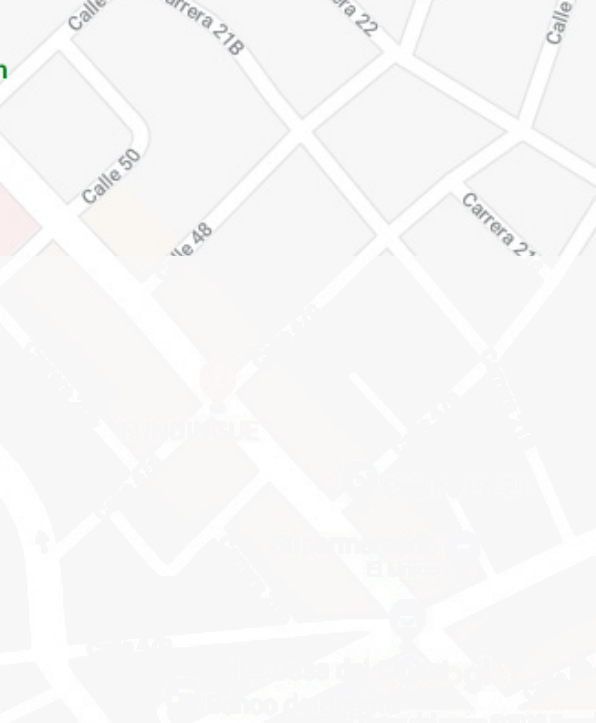

USOS Y

ACTIVIDADES

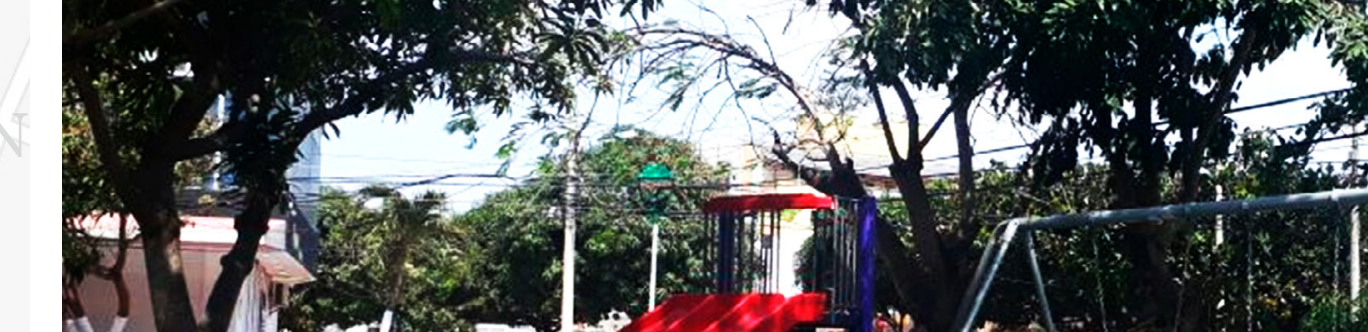

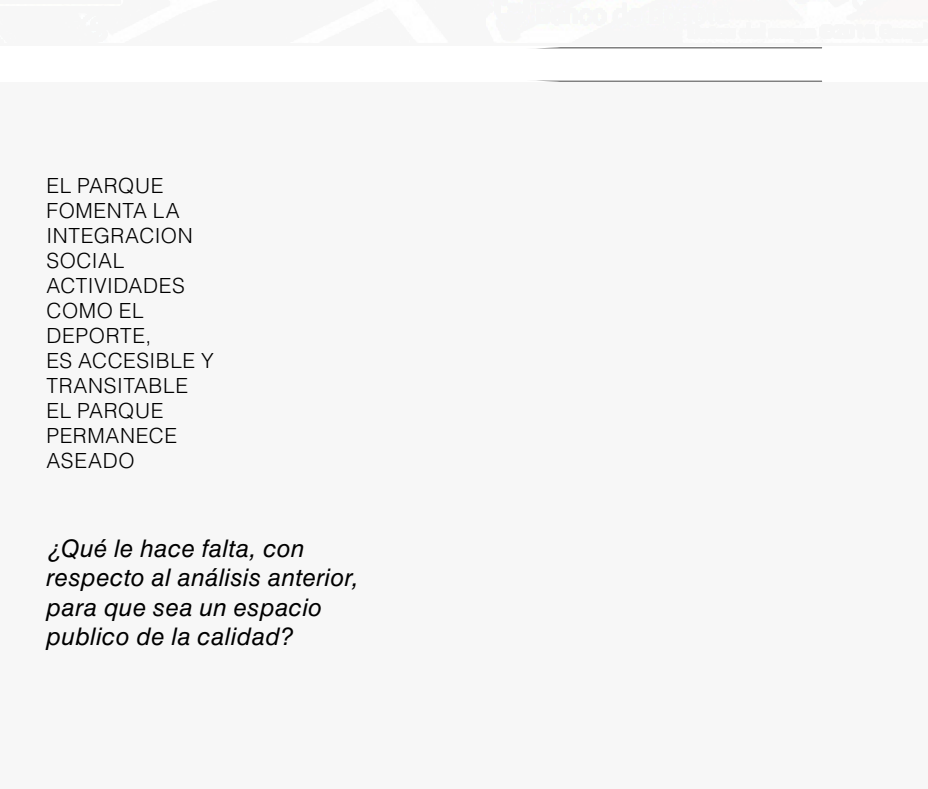

T

2.02, 3.
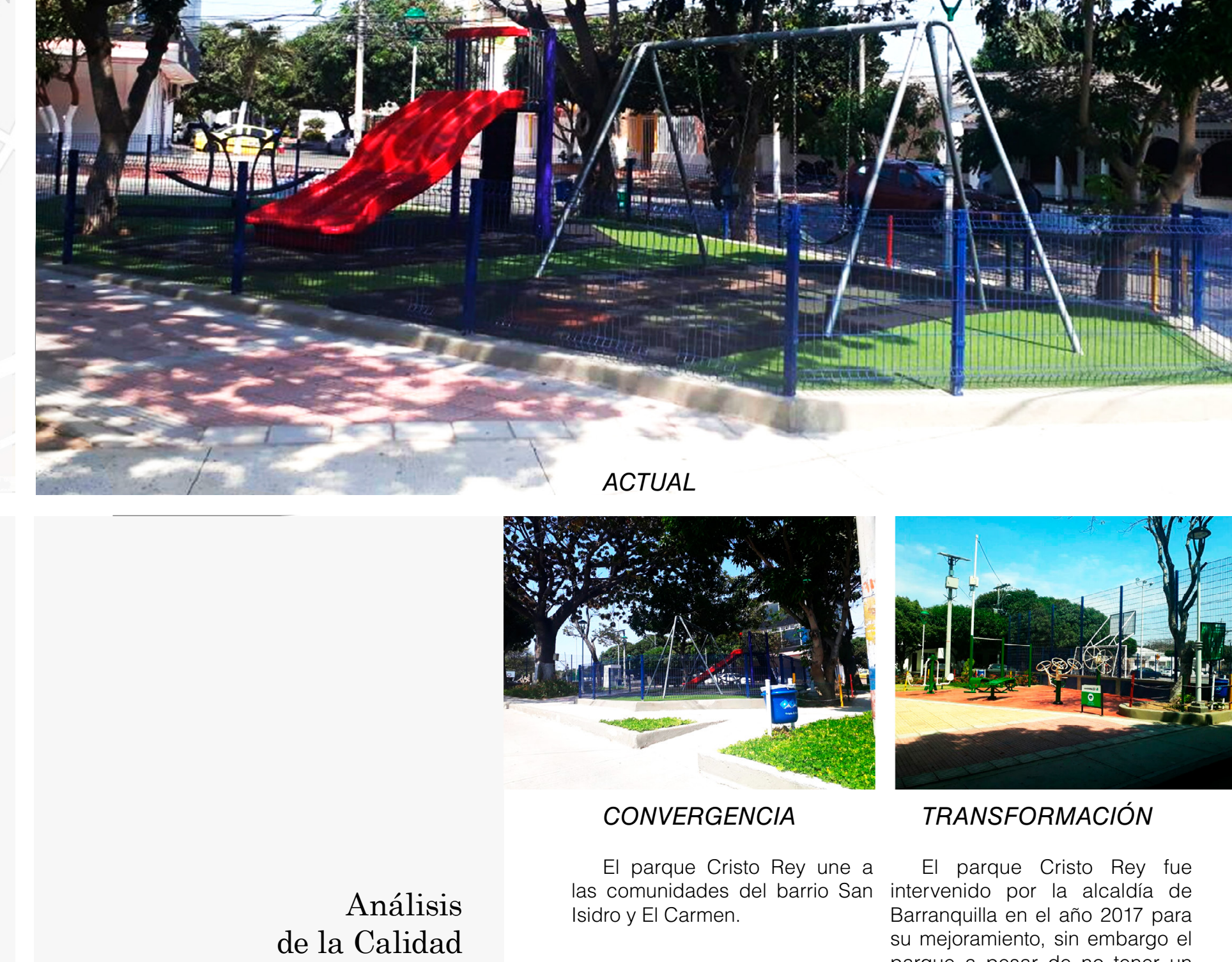

de la Calidad
del espacio Público

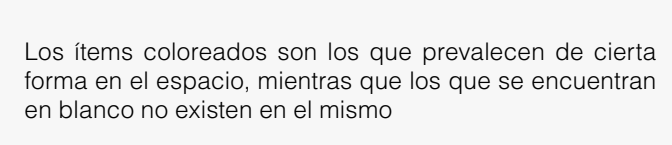

CONVERGENCIA

TRANSFORMACIÓN

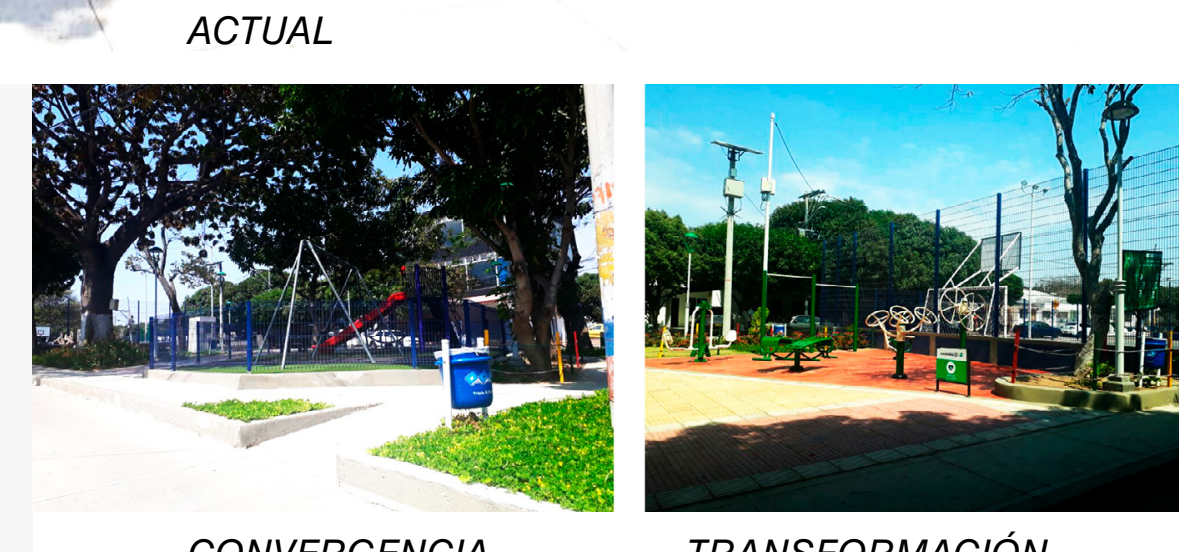

$\begin{array}{ll}\text { El parque Cristo Rey une a } & \text { El parque Cristo Rey fue } \\ \text { las comunidades del barrio San intervenido por la alcaldia de } & \text { de } \\ \text { Isidro y El Carmen. } & \text { Barranquilla en el año } 2017 \text { para }\end{array}$

su mejoramiento, sin embargo e

adecuada anteriormente, siempre fue utilizado, conservado y manten
la comunidad del barrio. 


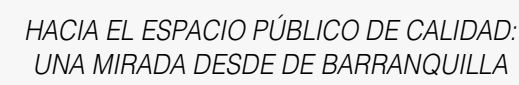

Con éste análisis se obtuvieron diferentes factores que nos permitieron determinar la utilidad e importancia de cada uno de estos parques en su contexto social y urbano; dando resultados favorables en algunos y adversos en otros. Los parques simbolizan proyección mas evidente de una arquitectura relacional, y no plasmar en ellos la identidad de ps usuarios y hacer invisibles su participación, hará que los espacos publicos en las ciudades sean Coniunto a so sería relevante Coner un a enado a la comunicad en general para que día a día vele por lo que para que día a día vele oda ella una buena práctica de a cultura ciudadana que pueda generar un acercamiento afectivo on el espacio público y apropiarse de él; Y por último creer que a ciudad está abierta a muchos proyectos que dan la cara por e espacio público.

\section{Parque Springfield}

LOCALIZACIÓN

Carrera 71 con calle 90

ANTES (2015)
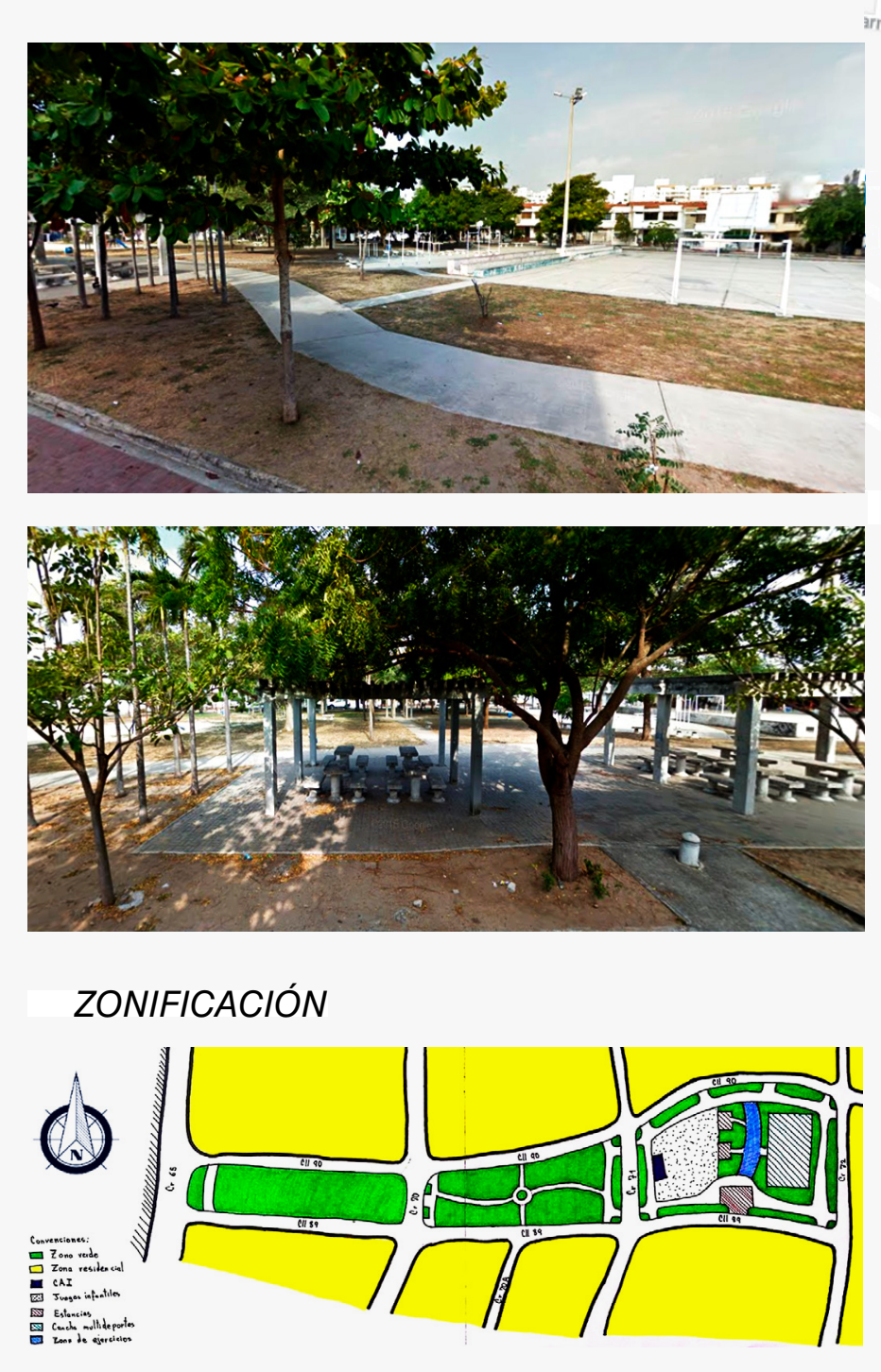

ate

¿Qué le hace eatla, con
respecto al analisis anterior

respecto al analisis ant
para que sea un essacic
publico del la calidad?

Análisis

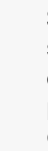

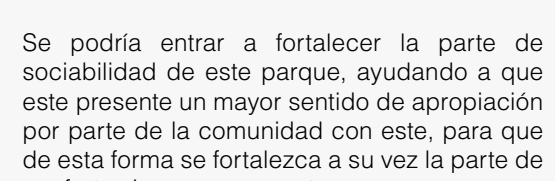

de la Calidad del espacio Público

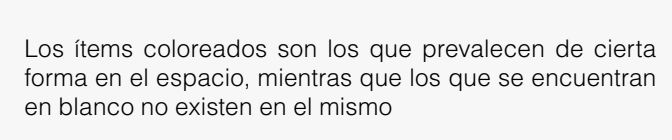

CONVERGENCIA

El parque Springfield une a las
comunidades del barrio de Villa
Carolina y Tivoli. tuncionalidad. Cabe resaltar que te de esté, se generababan activiTRANSFORMACIÓN dades como robos, expendio de El parque de Springfield ha que la implantación de este CAI sido transformado en los últimos en el parque mejoro la calidad de
años, y ha sido ometido a mante- vida de la población de sus alre- 


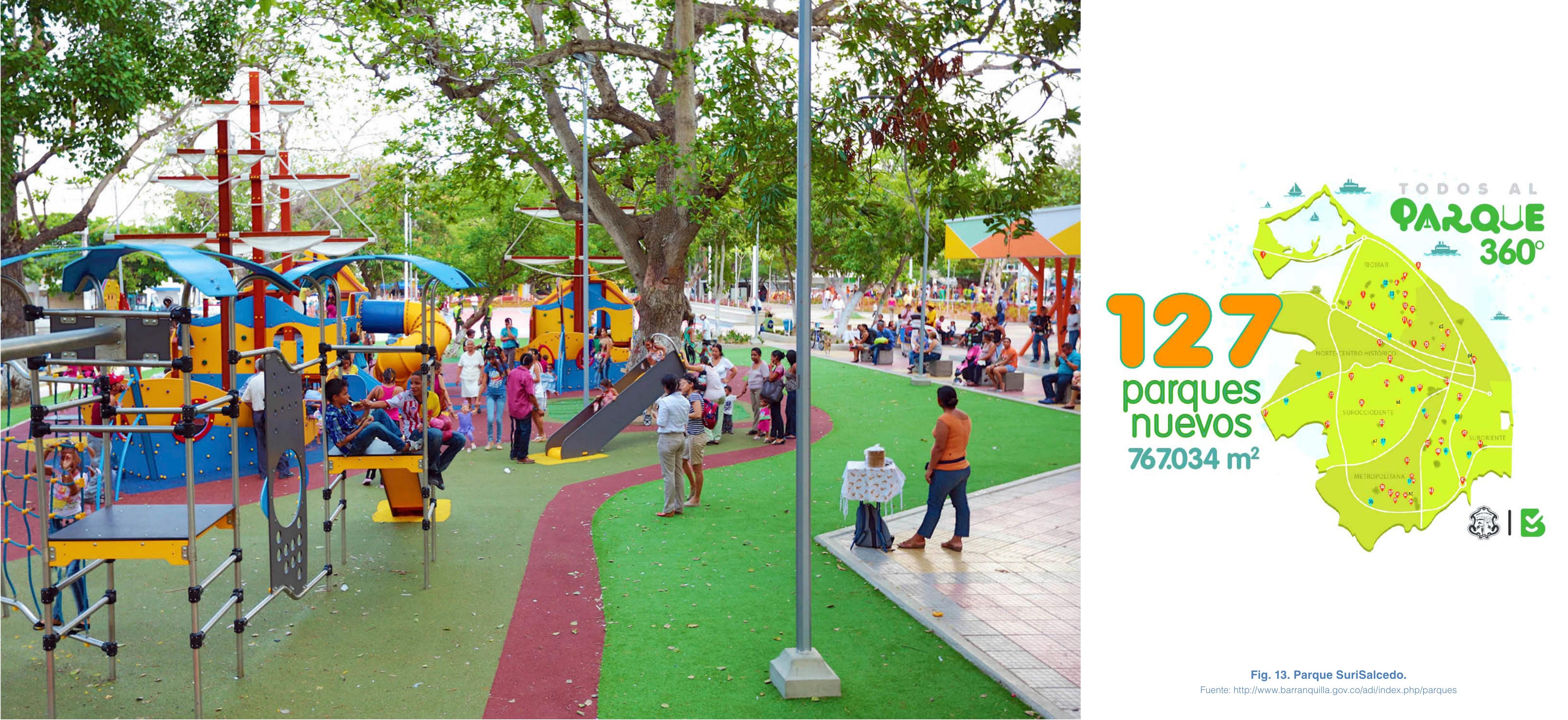




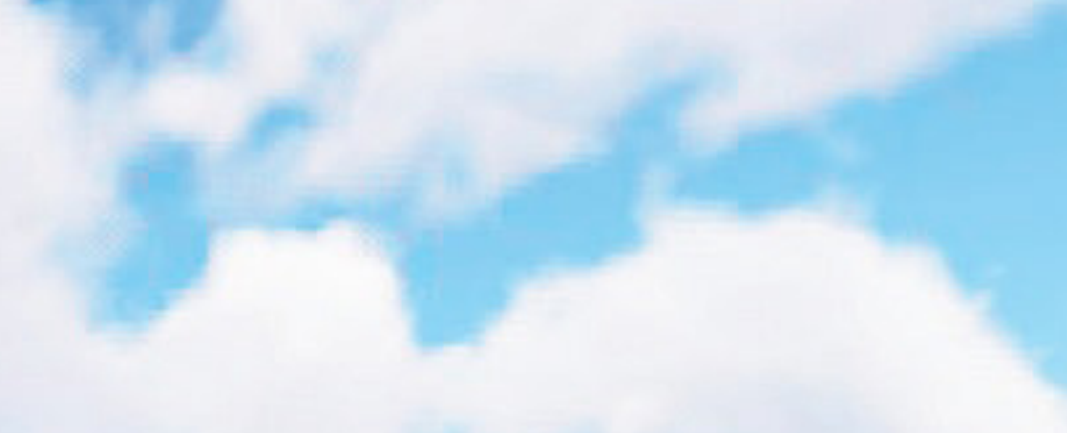

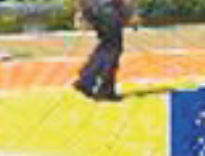

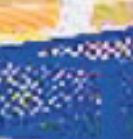

8

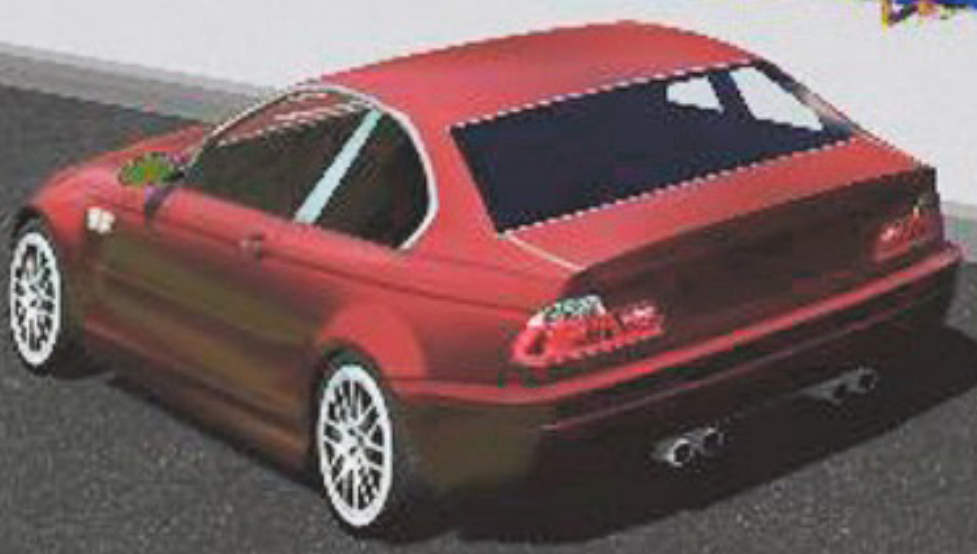

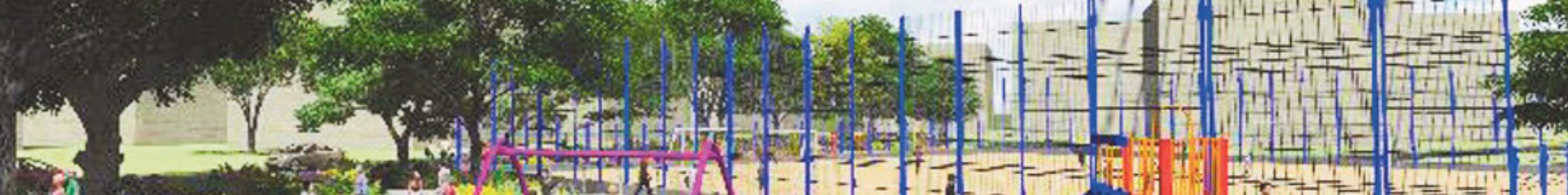

\section{$2+-1,2$}

$\rightarrow \infty$

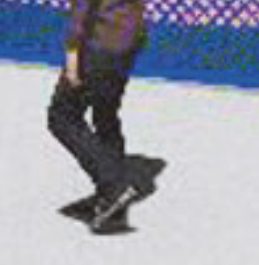

\section{REFERENCIAS}

Alcaldía de Barranquilla. (2012). Plan de Ordenamiento Territorial. Recuperado de http:I//www.barranquilla.gov plan-ordenamiento-territorial/reglamentacion-complementaria-pot

Borja, J. y Muxi, Z. (2000). El espacio público, ciudad y ciudadanía. Barcelona: Electa. Recuperado de https://www.researchgate.net/ tion/31731154_EL_tsezio ciudad y ciudadania_Boria Z hMuxi_prol_de

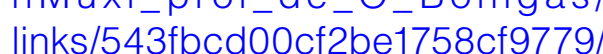
El-espacio-público-ciudad-y-ciudadania-J-Borja-Z-Muxi-prol-de-OBohigas.pdf

Correa, J. (2013). La ciudad no es un reloj. Consideraciones sobre lamuerte Conslanificación y el propósito de lo $99 \%$ invisible Modulo Arquitectura CUC, 12(1) 45-60. Recuperado de https:/revistascienificas cuc du co/moduloarquitecturacuc/article/ view/38/pdf_18

Osorio, H. y Rojas, E. (2013). Andar y movilidad sostenible. Modulo Arquitectura CUC, 12(1). 27-44. Recupecuc edu co/moduloarquitecturacuc article/view/37/pdf_17 
Padilla, S. (2015). Producción de espacio público [X] Participación ciudadana. El proyecto de espacio público resultado de procesos de participación ciudadana. [Tesis doctoral]. Universitat de Barcelona, España. Recuperado de http://hdl.handle. net/10803/309288

Paramo, P. y Burbano, A.M. (2014). Los usosy la apropiación del espacio público para el fortalecimiento de la democracia. Revista de Arquitectura, 16(1). 6-15. Recuperado de http://www.redalyc.org/ pdf/1251/125138774002.pdf

PNUMA (2003). Proyecto GEO Ciudades 10 años. ONU. Recuperado de http:// www.pnuma.org/deat1/pdf/Geo_ Ciudades(1-147)WEB11mayo.pdf

República de Colombia. Consejo Nacional de Política Económica y Social, Departamento Nacional de Planeación. (2012).

Documento Conpes 3718.Política Nacional de espacio público Recuperado de http://www.minambiente.gov. co/images/AsuntosambientalesySectorialyUrbana/pdf/Gestion_urbana/ espacio_publico/CONPES_3718_ de_2012_-_Política_Nacional_de_ Espacio_Público.pdf
República de Colombia. Presidencia de la República. (4 de agosto de 1998). Por el cual se reglamenta el manejo del espacio público en los planes de ordenamiento territorial. [Decreto 1504]. Recuperado de http://extwprlegs1.fao.org/docs/pdf/col150225. pdf

Rocha, D. (2013). Paisaje urbano e inseguridad ciudadana en la ciudad de Barranquilla. Modulo Arquitectura CUC, 12(1). 183-200. Recuperado de https://revistascientificas.cuc.edu. $\mathrm{co/moduloarquitecturacuc/article/}$ view/45/pdf_25

Yori, C. (2017). Lugar y territorio. Bogotá, D.C.: EdiSion. 